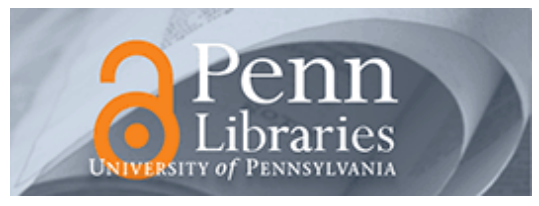

University of Pennsylvania

ScholarlyCommons

Finance Papers

Wharton Faculty Research

$10-2015$

\title{
Arbitrage Asymmetry and the Idiosyncratic Volatility Puzzle
}

Robert F. Stambaugh

University of Pennsylvania

Jianfeng Yu

Yu Yuan

Follow this and additional works at: https://repository.upenn.edu/fnce_papers

Part of the Finance and Financial Management Commons

\section{Recommended Citation}

Stambaugh, R. F., Yu, J., \& Yuan, Y. (2015). Arbitrage Asymmetry and the Idiosyncratic Volatility Puzzle.

The Journal of Finance, 70 (5), 1903-1948. http://dx.doi.org/10.1111/jofi.12286

This paper is posted at ScholarlyCommons. https://repository.upenn.edu/fnce_papers/178

For more information, please contact repository@pobox.upenn.edu. 


\title{
Arbitrage Asymmetry and the Idiosyncratic Volatility Puzzle
}

\author{
Abstract \\ Buying is easier than shorting for many equity investors. Combining this arbitrage asymmetry with the \\ arbitrage risk represented by idiosyncratic volatility (IVOL) explains the negative relation between IVOL \\ and average return. The IVOL-return relation is negative among overpriced stocks but positive among \\ underpriced stocks, with mispricing determined by combining 11 return anomalies. Consistent with \\ arbitrage asymmetry, the negative relation among overpriced stocks is stronger, especially for stocks less \\ easily shorted, so the overall IVOL-return relation is negative. Further supporting our explanation, high \\ investor sentiment weakens the positive relation among underpriced stocks and, especially, strengthens \\ the negative relation among overpriced stocks. \\ Disciplines \\ Finance and Financial Management
}




\title{
Arbitrage Asymmetry and the Idiosyncratic Volatility Puzzle
}

\author{
ROBERT F. STAMBAUGH, JIANFENG YU, and YU YUAN* \\ Journal of Finance, forthcoming
}

\begin{abstract}
Many investors purchase stock but are reluctant or unable to sell short. Combining this arbitrage asymmetry with the arbitrage risk represented by idiosyncratic volatility (IVOL) explains the negative relation between IVOL and average return. The IVOL-return relation is negative among overpriced stocks but positive among underpriced stocks, with mispricing determined by combining 11 return anomalies. Consistent with arbitrage asymmetry, the negative relation among overpriced stocks is stronger, especially for stocks less easily shorted, so the overall IVOL-return relation is negative. Further supporting our explanation, high investor sentiment weakens the positive relation among underpriced stocks and, especially, strengthens the negative relation among overpriced stocks.
\end{abstract}

\footnotetext{
* Stambaugh is with the Wharton School of the University of Pennsylvania and NBER, Yu is with the Carlson School of Management at the University of Minnesota and the PBC School of Finance at Tsinghua University, and Yuan is with the Shanghai Advanced Institute of Finance at Shanghai Jiao Tong University and the Wharton Financial Institutions Center at the University of Pennsylvania. We are grateful for helpful comments from Robert Hodrick, Xiaoji Lin, Ľuboš Pástor, Zhe Zhang, two anonymous referees, an associate editor, seminar participants at Carnegie Mellon University, the Federal Reserve Bank of Dallas, Georgetown University, HKUST, Michigan State University, Peking University, SAC Capital Advisors, Shanghai Advanced Institute of Finance, Singapore Management University, Southwest University of Finance and Economics, University of Calgary, University of Miami, University of Minnesota, University of Oxford, University of Pennsylvania, University of Southern California, University of Texas at Dallas, University of Toronto, and conference participants at the 2013 China International Conference in Finance, the 2013 SFS Cavalcade, the 2013 SIFR Conference on Rethinking Beta, the 2013 NBER Fall Asset Pricing Meeting, the 2013 Jacobs Levy Equity Management Center Conference, and the 2014 FMRC Conference on New Frontiers in Finance. We also thank Edmund Lee and especially Jianan Liu for excellent research assistance.
} 
DoEs A STOCK'S EXPECTED return depend on "idiosyncratic" volatility that does not arise from systematic risk factors? This question has been investigated empirically since virtually the inception of classical asset pricing theory. Earlier empirical investigations often find no relation, consistent with classical theory, or they find a positive relation between expected return and idiosyncratic volatility (IVOL). ${ }^{1}$ Much of the recent empirical research on this topic, beginning notably with Ang, Hodrick, Xing, and Zhang (2006), instead finds a negative relation between expected return and IVOL. As those authors discuss, earlier studies reporting a positive IVOL effect either do not examine IVOL at the individual-stock level or do not sort directly on IVOL. The negative relation appears robust to various specification issues raised by a number of recent studies (Chen, Jiang, Xu, and Yao, (2012)). While a positive relation is accommodated by various theoretical departures from the classical paradigm, the negative relation has presented more of a puzzle. ${ }^{2}$

This study presents an explanation for the observed negative relation between IVOL and expected return. We start with the principle that IVOL represents risk that deters arbitrage and the resulting reduction of mispricing. In keeping with previous literature, we refer to risk that deters arbitrage as arbitrage risk. ${ }^{3}$ We then combine this familiar concept with what we term arbitrage asymmetry: Many investors who would buy a stock they see as underpriced are reluctant or unable to short a stock they see as overpriced. ${ }^{4}$

Combining the effects of arbitrage risk and arbitrage asymmetry implies the observed negative relation between IVOL and expected return. To see this, first note that stocks with greater IVOL, and thus greater arbitrage risk, should be more susceptible to mispricing that is not eliminated by arbitrageurs. Among overpriced stocks, the IVOL effect in expected return should therefore be negative - those with the highest IVOL should be the most overpriced. Similarly, among underpriced stocks, the IVOL effect should be positive, as the highest IVOL stocks should then be the most underpriced. With arbitrage asymmetry, however, arbitrage should eliminate more underpricing than overpricing, due to the greater amount of arbitrage capital devoted to long positions as compared to short positions. As a result, the differences in the degree of underpricing associated with different levels of IVOL should be smaller than the IVOL-related differences in overpricing. That is, the negative IVOL effect among overpriced stocks should stronger than the positive IVOL effect among underpriced stocks. When aggregating across all stocks, the negative IVOL effect should therefore dominate and create the observed IVOL puzzle.

Arbitrage asymmetry exists at both the investor level and the stock level. Some investors are more able or willing to short than are other investors, and some stocks are more easily 
shorted than are other stocks. We present a simple model that incorporates both dimensions of arbitrage asymmetry. The basic mechanism, as in the above intuition, is that a given level of arbitrage risk is shared by more capital for long positions than for short positions. In addition, the model also implies that, among overpriced stocks, the negative IVOL effect should be stronger for stocks that are less easily shorted.

Our explanation of the IVOL puzzle is supported by the data. A key element of our empirical work is constructing a proxy for mispricing. For this purpose, we average each stock's rankings associated with 11 return anomalies that survive adjustment for the three factors of Fama and French (1993). Sorting stocks based on this composite anomaly ranking allows us to investigate the IVOL effect within various degrees of cross-sectional relative mispricing. As predicted, the IVOL effect is significantly negative (positive) among the most overpriced (underpriced) stocks, and the negative effect among the overpriced stocks is significantly stronger. Moreover, consistent with our simple model, we find that the negative IVOL effect among overpriced stocks is stronger for stocks less easily shorted, as proxied by stocks with low institutional ownership. We also find that the dependence of the IVOL effect on the direction of mispricing is quite robust to excluding smaller firms. At the same time, small-firm stocks also exhibit a stronger negative IVOL effect when overpriced, consistent with small-firm stocks being less easily shorted than large-firm stocks.

Additional implications of our explanation emerge when considering variation through time in the likely market-wide direction of mispricing. Periods when overpricing is its strongest are also those when we should observe the strongest negative IVOL effect among stocks classified as relatively overpriced by the cross-sectional anomaly ranking. Similarly, periods when underpricing is its strongest are those when we should observe the strongest positive IVOL effect among stocks classified as relatively underpriced. With arbitrage asymmetry, this variation in IVOL effects through time should be stronger for the stocks that are relatively overpriced. Thus, when aggregating across all stocks, the average negative relation between IVOL and expected return observed by previous studies should be stronger in periods when there is a market-wide tendency for overpricing.

To identify periods when a given mispricing direction is more likely, we use the index of market-wide investor sentiment constructed by Baker and Wurgler (2006). ${ }^{5}$ Consistent with the above predictions, the negative IVOL effect among overpriced stocks is significantly stronger following months when investor sentiment is high, and the positive IVOL effect among underpriced stocks is significantly stronger following months when investor sentiment is low. These inferences are further supported by finding that a time series regression 
of an IVOL return spread (high minus low) on investor sentiment produces a significantly negative coefficient for both the overpriced and underpriced stocks. Arbitrage asymmetry implies that this variation over time in IVOL effects should be stronger among the overpriced stocks. Consistent with this prediction, the time-series regression reveals significantly stronger sentiment-related variation in the IVOL effect among the overpriced stocks. When aggregating across stocks, the overall negative IVOL effect on expected return should be stronger following high sentiment, and this prediction is also confirmed in our results.

The relation between IVOL and expected return has been explored extensively in the literature. Numerous studies have considered interactions between IVOL and average anomaly returns, often entertaining the latter as reflecting mispricing. Several studies have also explored interactions between short selling and the IVOL effect. While various empirical results in previous studies are consistent with our explanation of the IVOL effect, those studies include neither our explanation of the IVOL effect nor our set of empirical results strongly supporting that explanation. The literature also includes various alternative explanations of the IVOL puzzle that may all be at work to some degree, but they are unable to explain the joint set of empirical results we present. The related literature is too extensive to review comprehensively, but as we present our evidence, we address the extent to which (i) our explanation of the IVOL puzzle is consistent with previous results and (ii) alternative explanations are inconsistent with our results.

The remainder of the paper is organized as follows. Section I discusses the joint roles of arbitrage asymmetry and arbitrage risk in allowing a stock's mispricing to survive the forces of arbitrage. The analysis includes the simple model mentioned above, as well as a discussion of how a given level of IVOL can contribute more to the arbitrage risk of short positions than of long positions. Section II describes our empirical measure of relative cross-sectional mispricing, based on a composite ranking that combines 11 return anomalies. Section III presents our basic cross-sectional results analyzing the effect of mispricing on the IVOL effect. We first use portfolio sorts to show that the IVOL effect is positive among underpriced stocks but is more strongly negative among overpriced stocks. We then use the cross-section of individual stocks to estimate the form of the relation between mispricing and the IVOL effect. Finally we show that the negative IVOL effect among overpriced stocks is stronger among stocks with low institutional ownership, for which short-sale impediments are likely to be more important. Section IV explores the time-series implications of our setting, using investor sentiment as a proxy for the likely direction of market-wide tendencies toward overpricing or underpricing. Section V shows that while the negative IVOL effect among overpriced stocks is stronger among smaller stocks, consistent with smaller stocks being 
shorted less easily, the dependence of the IVOL effect on mispricing is robust to eliminating smaller stocks. Section VI reviews the study's main conclusions.

\section{Arbitrage Risk and Arbitrage Asymmetry}

Our setting combines two familiar concepts, arbitrage risk and arbitrage asymmetry. Arbitrage risk is risk that deters arbitrage. Arbitrage asymmetry is the greater ability or willingness of an investor to take a long position as opposed to a short position when perceiving mispricing in a security.

Arbitrage risk is related to idiosyncratic volatility (IVOL). If arbitrageurs can neutralize their exposure to benchmark risks, a seemingly reasonable assumption, then idiosyncratic volatility, as opposed to total volatility, is more closely related to arbitrage risk. Pontiff (2006), for example, provides a simple setting in which a stock's IVOL represents its arbitrage risk. He shows that the greater is a stock's IVOL, the smaller is a mean-variance investor's desired position size for a given level of alpha (mispricing). In other words, higher IVOL implies greater deterrence to price-correcting arbitrage.

Arbitrage asymmetry is well established. The sizes of institutions engaged in shorting, such as hedge funds, are rather small in aggregate compared to the sizes of mutual funds and other institutions that do not short. Hong and Sraer (2014) place primary emphasis on this disparity in arguing that short-sale impediments are important. They cite the low use of actual shorting by mutual funds, often due to investment policy restrictions, as documented by Almazan, Brown, Carlson, and Chapman (2004), as well as mutual funds' low use of derivatives, as documented by Koski and Pontiff (1999). D'Avolio (2002) finds that shorting costs, while generally low, increase in the dispersion of opinion about a stock, consistent with a setting in which shorting becomes more expensive precisely when less optimistic investors would wish to short a stock whose price is driven up by more optimistic investors. Lamont (2012) discusses various impediments to short selling, and he also argues that impediments can become more severe precisely when a stock becomes more overpriced, sometimes due to action by a firm to deter shorting of its stock.

The first subsection below presents a simple model capturing the combined roles of arbitrage risk and arbitrage asymmetry. Mean-variance investors in a one-period setting are subject to arbitrage asymmetry when exploiting mispricing induced by noise traders. The basic mechanism at work is that, with arbitrage asymmetry, the amount of capital bearing 
a given degree of IVOL in shorting overpriced securities is less than the amount of capital bearing the same IVOL in buying underpriced securities. As a result, for a given level of IVOL, the demands of noise traders can exert a relatively greater effect on equilibrium alpha when those demands go in the direction of producing overpricing as opposed to underpricing.

Arbitrage asymmetry exists at both the investor level and the stock level. Some investors are more able or willing to short than other investors, and some stocks are more easily shorted than other stocks. Our model incorporates both investor-level and stock-level shorting impediments. To do so simply, within the modeling confines of an empirical study, we divide both stocks and investors into two groups each. One group of investors is more able to short than the other, and one group of stocks is more easily shorted than the other. Specifically, the less constrained group of investors can short all stocks, while the more constrained group of investors can short only the group of stocks more easily shorted.

Among stocks in high positive demand by noise traders, the model implies a negative relation between alpha and IVOL for these overpriced stocks. Similarly, among stocks with low or negative noise-trader demand, there is a positive relation between alpha and IVOL for these underpriced stocks. A key implication is that the negative relation among the overpriced stocks is steeper than the positive relation among the underpriced stocks. This implication abstracts from differences among stocks in shorting impediments, in that it aggregates across the two stock groups that differ in ease of shorting. Those stock-level differences play a role in the model as well. In particular, the negative relation between alpha and IVOL among overpriced stocks is steeper within the stocks less easily shorted than within those more easily shorted.

The simple one-period setting of the model includes arbitrage asymmetry, but arbitrage risk-IVOL — does not depend on whether a position is long or short. In that setting, what differs between long and short positions is the amount of capital that bears the arbitrage risk. In the second subsection below, we discuss how a given level of IVOL can translate to arbitrage risk that is itself asymmetric. In particular, short positions involve a greater risk of margin calls.

\section{A. A Simple Model}

Securities are held by mean-variance investors, index funds, and noise traders. The mean-variance investors have the single-period objective

$$
\max _{\omega}\left(\omega^{\prime} \mu-\frac{A}{2} \omega^{\prime} V \omega\right),
$$


where $\mu$ is the vector of expected excess returns on the $N$ risky assets, the $i$-th element of $\omega$ is the fraction of wealth invested in asset $i$, and $V$ is the variance-covariance matrix of returns, assumed to be of the form

$$
V=\sigma_{m}^{2} \beta \beta^{\prime}+\Sigma
$$

where $\sigma_{m}^{2}$ is the variance of the market return, $\beta$ is the vector of the assets' market betas, and $\Sigma$ is a diagonal matrix whose $i$-th diagonal element is $\sigma_{\epsilon, i}^{2}$, the idiosyncratic return variance of asset $i{ }^{6}$ The noise traders have asset demands given exogenously by the $N$-vector $z$, and $q$ is the fraction of the market owned by index funds. In this simplified setting, index funds are best viewed more broadly as including investors who limit deviations from a benchmark portfolio. We assume that the elements of $z$ and $\beta$ are uncorrelated in the cross section, and we also assume that the market equity premium, $\mu_{m}$, is the same as what it would be if $z$ were the zero vector. Specifically, $\mu_{m}=A \sigma_{m}^{2}$.

The mean-variance investors are composed of two groups, $I_{M}$ and $I_{H}$. Group $I_{M}$ has total stock-market capital $M$, which is allocated across stocks according to the vector of optimal weights $\omega_{M}$. Investors in that group can short only the first $N_{1}$ of the $N$ stocks. Investor group $I_{H}$ has stock-market capital $H$ and optimal weights $\omega_{H}$. Those investors can short all $N$ stocks. Define $s$ as the vector of total market capitalizations of the assets, and note that market clearing requires

$$
M \omega_{M}+H \omega_{H}=(1-q) s-z .
$$

Define the "excess" noise-trader demand for asset $i$ as

$$
y_{i}=(1-q) s_{i}-z_{i}
$$

where $s_{i}$ and $z_{i}$ denote the $i$-th elements of $s$ and $z$.

For each asset $i$, this model delivers the following result for $\alpha_{i}\left(=\mu_{i}-\beta_{i} \mu_{m}\right)$ as $N$ grows large with $N_{1}$ as a constant fraction of $N$. If the investors in group $I_{M}$ (constrained group) have a nonzero position in stock $i$ (i.e., $\omega_{M, i} \neq 0$ ), then

$$
\alpha_{i}=A y_{i} \frac{\sigma_{\epsilon, i}^{2}}{M+H}
$$

If the investors in group $I_{M}$ have a zero position in stock $i$, (i.e., $\omega_{M, i}=0$ ), then

$$
\alpha_{i}=A y_{i} \frac{\sigma_{\epsilon, i}^{2}}{H}
$$

Derivations are provided in the Appendix. 
For a given level of excess noise-trader demand, $y_{i}$, equations (5) and (6) reveal the effects of arbitrage asymmetry in the relation between $\alpha_{i}$ and arbitrage risk $\left(\sigma_{\epsilon, i}\right)$. Among underpriced stocks with a given positive $y_{i}$, the relation between $\alpha_{i}$ and $\sigma_{\epsilon, i}$ is positive, whereas it is negative for overpriced stocks with a given negative $y_{i}$. The positive relation for underpriced stocks is given by equation (5), in which $M+H$ appears in the denominator. The negative relation among overpriced stocks is also given by equation (5) for the first $N_{1}$ stocks that investor group $I_{M}$ (constrained group) can short. For the remaining overpriced stocks, the negative relation is instead given by equation (6), in which only $H$ appears in the denominator, giving a steeper relation than in equation (5). Thus, when averaging across stocks in the groups more easily and less easily shorted, the negative relation between $\alpha_{i}$ and $\sigma_{\epsilon, i}$ for overpriced stocks is steeper than the positive relation for the underpriced stocks. This implication reflects investor-level arbitrage asymmetry, in that it averages across the stock-level differences in shorting ease. The result obtains also in the special case of no such stock-level differences, i.e., the case in which investors in group $I_{M}$ cannot short any of the $N$ stocks $\left(N_{1}=0\right)$.

The role of stock-level arbitrage asymmetry also emerges from equations (5) and (6). Among the overpriced stocks, the negative relation between $\alpha_{i}$ and $\sigma_{\epsilon, i}$ for stocks in the group less easily shorted is given by the steeper relation in equation (6). In contrast, the negative relation for overpriced stocks in the more easily shorted group is given by the less steep relation in equation (5).

We can see the basic mechanism at work in this simple model. When arbitrage risk is borne by a smaller pool of capital $-H$ as opposed to $M+H$ - the role of that risk in the resulting equilibrium mispricing $\left(\alpha_{i}\right)$, ceteris paribus, is correspondingly greater. To say more about alphas requires assumptions about the size and distribution of noise trader demands, as well as risk tolerance, and such considerations must lie beyond our scope here.

\section{B. Asymmetric Arbitrage Risk}

In the setting above there is arbitrage asymmetry, but arbitrage risk does not depend on whether a position is long or short. Instead what differs between long and short positions is the amount of capital bearing the arbitrage risk. In addition to that source of asymmetry, however, the risks to arbitrageurs can differ for long versus short positions for a given level of volatility. One source of arbitrage risk, often termed "noise-trader" risk (e.g., Shleifer and Vishny, 1997), is that adverse price moves can require additional capital in order to 
maintain positions that involve shorting or leverage. ${ }^{7}$ Such adverse moves can force capitalconstrained investors to reduce their positions before realizing profits that would ultimately result from corrections of mispricing. Savor and Gamboa-Cavazos (2014) present empirical evidence on short positions that is consistent with this effect. They find that short sellers typically reduce their positions following adverse price moves, particularly if the short selling appears to be aimed at profiting from overpricing.

When IVOL is higher, substantial adverse price moves are more likely, but such moves can have different implications depending on whether the position is long or short. In general, shorting requires that a margin deposit be maintained at some percentage of position size. If the price of the shorted stock rises, increasing the position size, additional margin capital can be required. A purchaser who does not employ leverage does not face margin calls, so in that case the asymmetry in the effects of adverse price moves is obvious. ${ }^{8}$ Asymmetry is still present even if purchases are made on margin. To see this, note first that a position's margin ratio, which must typically be maintained above a specified maintenance level, is computed as

$$
m=\frac{\text { equity }}{\text { position size }}
$$

Now consider identically sized short and long positions that subsequently experience identical adverse rates of return on their underlying securities. Given the identical absolute return magnitudes, both positions lose identical amounts of equity, so they still have identical values for the numerator in (7). The new denominators differ from each other, however. The position size decreases for the long position but increases for the short position, so the short position's $m$ declines by a greater amount.

These asymmetric effects of an adverse return imply that the probability of hitting a maintenance margin level is generally more sensitive to the short leg's IVOL than to the long leg's IVOL. Figure 1 displays the probability of a long-short strategy hitting a $25 \%$ maintenance margin level within the next 12 months when the current margin level is 35\%a 10\% cushion. The current long and short positions are of equal size and have monthly IVOL values between $1 \%$ and $5 \%$ - essentially the range for IVOLs on portfolios that we construct in Section III. The long (short) leg has a monthly alpha of $0.5 \%(-0.5 \%)$, and both legs have betas equal to 1. The market portfolio's monthly return has mean of $0.8 \%$ and standard deviation of $5 \%$, and the monthly riskless rate is $0.3 \%$. The asymmetric role of IVOL is evident in the plot, which reveals that the probability of a margin call is more sensitive to the IVOL of the short leg. For example, when the long-leg IVOL is $3 \%$ per month, there is nearly a fivefold increase in the margin-call probability when the short-leg 
IVOL increases from $1 \%$ to $5 \%$. When the long and short legs switch roles in that example, the corresponding increase in probability is less than twofold.$^{9}$

\section{Identifying Potential Mispricing}

In our setting, mispricing is essentially the difference between the observed price and the price that would otherwise prevail in the absence of arbitrage risk and other arbitrage impediments. Of course, mispricing is not directly observable, and the best we can do is to construct an imperfect proxy for it. An obvious resource for this purpose is the evidence on return anomalies, which are differences in average returns that challenge risk-based models. We construct a mispricing measure based on 11 return anomalies taken from the literature. To our knowledge, the 11 anomalies constitute a fairly comprehensive list of those that survive adjustment for the three factors of Fama and French (1993). The same anomalies are used by Stambaugh, Yu, and Yuan (2012). We list them here along with the principal studies documenting them. Brief descriptions are provided in the Appendix.

1. Financial Distress (Campbell, Hilscher, and Szilagyi (2008))

2. O-score Bankruptcy Probability (Ohlson (1980))

3. Net Stock Issues (Ritter (1991), Loughran and Ritter (1995), Fama and French (2008))

4. Composite Equity Issues (Daniel and Titman (2006))

5. Total Accruals (Sloan (1996))

6. Net Operating Assets (Hirshleifer, Hou, Teoh, and Zhang (2004))

7. Momentum (Jegadeesh and Titman (1993))

8. Gross Profitability (Novy-Marx (2013))

9. Asset Growth (Cooper, Gulen, and Schill (2008))

10. Return on Assets (Fama and French (2006), Chen, Novy-Marx, and Zhang (2010))

11. Investment-to-Assets (Titman, Wei, and Xie (2004), Xing (2008))

Our mispricing measure, a composite rank based on a stock's various stock characteristics, is best interpreted as representing potential mispricing, possibly due to noise traders, rather than as the actual mispricing that survives after arbitrage. In particular, a firm with a less extreme mispricing rank but high IVOL could potentially have more mispricing that survives arbitrage than does a firm with a more extreme ranking but low IVOL.

We combine the anomalies to produce a univariate monthly measure that correlates with the degree of relative mispricing in the cross section of stocks. While each anomaly is itself a mispricing measure, our objective in combining them is to produce a single measure that 
diversifies away some noise in each individual anomaly and thereby increases precision when exploring the empirical implications of our setting.

Our method for combining the anomalies is simple. For each anomaly, we assign a rank to each stock that reflects the sorting on that given anomaly variable, where the highest rank is assigned to the value of the anomaly variable associated with the lowest average abnormal return, as reported in the literature. For example, one documented anomaly is that high asset growth in the previous year is followed by low return (Cooper, Gulen, and Schill (2008)). We therefore rank firms each month by asset growth, and those with the highest growth receive the highest rank. The higher the rank, the greater the relative degree of overpricing according to the given anomaly variable. A stock's composite rank is then the arithmetic average of its ranking percentile for each of the 11 anomalies. Thus, we refer to the stocks with the highest composite ranking as the most "overpriced" and to those with the lowest ranking as the most "underpriced." The mispricing measure is purely cross-sectional, so it is important to note that these designations at best denote only relative mispricing. At any given time, for example, a stock identified as the most underpriced might actually be overpriced. The intent of the measure is simply that such stocks would then be the least overpriced within the cross section. We return to this point later, when investigating the role of investor sentiment over time. Throughout the study, the stock universe each month consists of all NYSE/AMEX/NASDAQ stocks with share prices greater than five dollars and for which at least five of the anomaly variables can be computed. We remove penny stocks because Chen, Jiang, Xu, and Yao (2012) find that the IVOL effect - the puzzle we seek to explain - is especially robust when those stocks are excluded. The five-anomaly requirement typically eliminates about $10 \%$ of the remaining stocks.

Evidence that our mispricing measure is effective in diversifying some of the noise in anomaly rankings can be found in the range of average returns produced by sorting on our measure. For example, in each month we assign stocks to ten categories based on our measure and then form a value-weighted portfolio for each decile. The following month's spread in benchmark-adjusted returns between the two extreme deciles averages $1.48 \%$ over our sample period, 8/1965-1/2011. (The returns are adjusted for exposures to the three equity benchmarks constructed by Fama and French (1993): MKT, SMB, and HML.) In comparison, if value-weighted decile portfolios are first formed for each individual anomaly ranking, and then the returns on those portfolios are combined with equal weights across the 11 anomalies, the corresponding spread between the extreme deciles is $0.87 \%$. In other words, averaging the anomaly rankings produces an extra 61 basis points per month as compared to averaging the anomaly returns. (The t-statistic of the difference is 4.88.) 
We also find in the above comparison that ranking on our mispricing measure creates additional abnormal return primarily among the stocks classified as overpriced. For example, of the 61-basis-point improvement in the long-short return spread reported above, 57 basis points come from the most overpriced portfolio - the short leg of the corresponding arbitrage strategy - and only 4 basis points come from the most underpriced - the long leg. This asymmetry in improvement in arbitrage profits is consistent with arbitrage asymmetry: With the latter asymmetry, one expects overpricing to be greater than underpricing, so a better identification of mispricing should yield greater improvement in arbitrage profits for overpriced stocks than for underpriced stocks.

\section{IVOL Effects in the Cross-Section}

We compute individual-stock IVOL, following Ang, Hodrick, Xing, and Zhang (2006), as the standard deviation of the most recent month's daily benchmark-adjusted returns. The latter returns are computed as the residuals in a regression of each stock's daily return on the three factors defined by Fama and French (1993): MKT, SMB, and HML. We estimate IVOL in this manner primarily to address the puzzling negative relation between IVOL and expected return found by that study and confirmed by a number of subsequent studies using the same approach. There are alternative approaches to estimating IVOL, such as the EGARCH model in Fu (2009) based on monthly returns, but the simple estimate used here performs relatively well as a measure of forward-looking IVOL. For example, Jin (2013) compares a number of IVOL estimation methods in terms of their cross-sectional rank correlations with realized daily idiosyncratic volatility in the subsequent month. She finds that past realized volatility, as used here, outperforms GARCH and EGARCH estimates and performs similarly to estimates from a simple autoregressive model.

In this section we investigate the role of mispricing in the cross-sectional relation between alpha and IVOL. Subsection A presents results based on portfolio sorts, an approach robust to the functional form of the relation between the IVOL effect and mispricing. We then estimate that functional form in Subsection B, using the cross-section of individual stocks. The role of stock-level arbitrage asymmetry is explored in Subsection C, using institutional ownership as a proxy for shorting impediments. 


\section{A. Mispricing and IVOL Effects}

Each month, portfolios are constructed by sorting on individual stock IVOL, forming five categories, and then sorting independently by the mispricing measure, again forming five categories. We then construct 25 portfolios defined by the intersections of this $5 \times 5$ sort, and we value weight the stocks' returns when computing portfolio returns. Panel A of Table I reports the typical individual stock IVOL within each portfolio. Note that, given the independent sorting, the range for IVOL is very similar across the different levels of mispricing. The IVOL within each mispricing level, reported in the last column, increases monotonically from the most underpriced to the most overpriced stocks. This pattern also emerges from Panel B of Table I, which reports the average number of stocks in each portfolio: the high-IVOL portfolio contains significantly more (less) stocks than the low-IVOL portfolio among the most overpriced (underpriced) stocks. To the extent that overpriced stocks are more likely to be shorted, a related result appears in Duan, $\mathrm{Hu}$, and McLean (2010), who find that stocks with high short interest have higher IVOL.

The tendency for overpriced stocks to have high IVOL is consistent with combining two effects. First, high-volatility stocks are difficult to value accurately and thus especially susceptible to being viewed with excess optimism or pessimism by noise traders (e.g., Baker and Wurgler, 2006). Second, noise traders face shorting impediments that constrain negative demands for stocks viewed too pessimistically, but there is no similar constraint on positive demands fueled by excess optimism. Therefore, these combined roles of volatility and shorting impediments imply that high-volatility stocks are more likely to be overpriced than underpriced as a result of excessive optimism or pessimism - sentiment - possessed by noise traders. Of course, non-sentiment components of noise-trader demand, such as those reflecting slow recognition of information relevant even to stocks easier to value, can contribute to mispricing at all levels of volatility. Our explanation of the IVOL puzzle is neither supported nor refuted by volatility-related components of noise trader demands; the model presented earlier treats such demands (denoted by $z$ ) as exogenous.

Table II, which contains the first set of our main results, reports average benchmarkadjusted monthly returns for each of the 25 portfolios. We see evidence consistent with the

role of IVOL-driven arbitrage risk in mispricing. Among the stocks most likely to be mis[Table

priced, as identified by our mispricing measure, we expect to see the magnitude of mispricing increase with IVOL. The patterns in average returns are consistent with that prediction. For the most overpriced stocks, the average returns are negative and monotonically decreasing in IVOL, with the difference between the highest- and lowest-IVOL portfolios equal to $-1.50 \%$ 
per month (t-statistic: -7.36). ${ }^{10}$ For the most underpriced stocks, the average returns are positive and generally increasing in IVOL, with the difference between the highest- and lowest-IVOL portfolios equal to $0.41 \%$ per month (t-statistic: 2.16 ). For the stocks in the middle of the mispricing scale, there is no apparent IVOL pattern, and the highest-versuslowest difference is only $-0.10 \%$ per month (t-statistic: -0.53 ). The role of mispricing in determining the strength and direction of IVOL effects is readily apparent in Figure 2, which plots the average benchmark-adjusted returns reported in Table II.

Also evident in Table II and Figure 2 is the asymmetry in IVOL effects predicted by arbitrage asymmetry. Recall that the IVOL breakpoints are the same across the mispricing quintiles in Table II and that the ranges of average IVOLs are therefore very similar across the mispricing quintiles. As a result, we can see that the negative IVOL effect among the overpriced stocks is stronger than the positive IVOL effect among the underpriced stocks. The negative highest-versus-lowest difference among the most overpriced stocks is 3.7 times the magnitude of the corresponding positive difference among the most underpriced stocks.

Given the asymmetry in the strengths of the negative and positive IVOL effects among ovepriced and underpriced stocks, aggregating across all stocks results in the negative overall IVOL effect reported in the last row of Table II. Among all stocks, consistent with the IVOL puzzle observed in the literature, average return is monotonically decreasing in IVOL, with the highest-versus-lowest difference equal to $-0.78 \%$ per month (t-statistic: -5.50 ).

Chen, Jiang, Xu, and Yao (2012) show that the overall negative IVOL effect is very robust, especially when penny stocks and other very illiquid stocks are excluded. Excluding such stocks is relevant in particular to the results of Huang, Liu, Rhee, and Zhang (2010), who argue that IVOL proxies for a return-reversal effect, Han and Lesmond (2011), who argue that the IVOL effect is due to market microstructure biases, and Bali and Cakici (2008), who argue that equal-weighted portfolios do not show a robust negative IVOL effect. Chen et al. find that the results in support of these three studies are not robust to excluding penny stocks and microcaps. ${ }^{11}$ Other studies reporting a negative relation include Jiang, Xu, and Yao (2009) and Guo and Savickas (2010). As Ang, Hodrick, Xing, and Zhang (2006) discuss, the earlier studies finding a positive IVOL effect either do not examine IVOL at the individual-stock level or do not sort on IVOL directly. A more recent study by Fu (2009) finds a positive IVOL effect, rather than a negative one, but Guo, Kassa, and Ferguson (2014) and Fink, Fink, and He (2012) argue that the positive relation between expected return and IVOL found by $\mathrm{Fu}$ owes to the use of contemporaneous information in the conditional variance model, and that the positive relation does not survive after controlling for such 
information. Rachwalski and Wen (2012) find that expected return is negatively related to recent IVOL but positively related to less recent IVOL. Similarly, Cao and Xu (2010) find that expected return is negatively related to short-run IVOL but positively related to long-run IVOL. Short-run volatility, in the months immediately following the identification of mispricing, seems especially relevant to arbitrageurs, and to that extent our explanation applies to the negative short-run relation. Our explanation does not imply a positive long-run relation.

The switch from a negative to a positive IVOL effect when moving from overpriced stocks to underpriced stocks is previously reported by Cao and Han (2014). Those authors also explore the role of IVOL-related arbitrage risk in mispricing by sorting stocks based on a composite of anomaly rankings, and they also find a significantly negative (positive) IVOL effect among the relatively overpriced (underpriced) stocks. Their results do not display a substantial asymmetry in the strength of those IVOL effects, nor do they discuss asymmetry or the IVOL puzzle. A potential reason that asymmetry does not emerge as a feature of their study is that their anomaly ranking measure could contain less information about mispricing, in that it combines only four anomalies, instead of our 11, and two of those four are size and book-to-market, for which a mispricing interpretation must contend with a significant literature arguing that those variables instead proxy for risk. Studies by Boehme, Danielson, Kumar, and Sorescu (2009) and Duan, Hu, and McLean (2010) find there is a strong negative IVOL effect among stocks with high shorting activity, but among stocks with low shorting activity the negative relation becomes flatter, or even weakly positive in the case of the first study. Such a result is consistent with our explanation if shorting activity is higher among overpriced stocks.

An additional implication of our setting is that the degree of mispricing, especially overpricing, should be greater among high-IVOL stocks than among low-IVOL stocks. We see this implication supported as well. The difference in average portfolio returns between the most overpriced stocks and the most underpriced stocks is negative and decreasing in IVOL, as shown in the next to last row in Table II. The difference between that short-long difference for the highest-IVOL portfolios versus the lowest-IVOL portfolios is $-1.91 \%$ per month (t-statistic: -7.62). These results are consistent with those of Jin (2013), who finds that long-short spreads on each of ten anomalies are more profitable among high-IVOL stocks than among low-IVOL stocks, and that this difference in profitability is attributable primarily to the short legs of each strategy. Jin's study is to our knowledge unique in noting this consistent asymmetry in the short legs versus the long legs across many anomaly spreads, but numerous other studies find that various return anomalies are stronger among high- 
IVOL stocks. Such anomalies include those based on closed-end fund discounts (Pontiff (1996)), index inclusions (Wurgler and Zhuravskaya (2002)), post-earnings-announcement drift (Mendenhall (2004)), the value premium (Ali, Hwang, Trombley (2003)), momentum (Zhang (2006)), accruals (Mashruwala, Rajgopal, and Shevlin (2006), Pincus, Rajgopal, and Venkatachalam (2007), Li and Sullivan (2011)), "Siamese twin" stocks (Scruggs (2007)), insider trades and share repurchases (Ben-David and Roulstone (2010)), long-term reversal (McLean (2010)), asset growth (Li and Sullivan (2011), Lipson, Mortal, and Schill (2011)), Li and Zhang (2012), Lam and Wei (2013), equity issuance (Larrain and Varas (2013)), investment to assets (Li and Zhang (2012)), and return on assets (Wang and Yu (2010)).

Alternative explanations of the IVOL puzzle appear in a number of studies, but they seem challenged to accommodate our empirical results above, particularly the switch in sign of the IVOL effect when moving across the mispricing spectrum. For example, a negative IVOL effect could reflect a preference for idiosyncratic positive skewness (Barberis and Huang (2008), Boyer, Mitton, and Vorkink (2010)) or for lottery-like payoffs captured by maximum past return (Bali, Cakici, and Whitelaw (2011)). In results available in the on-line appendix, we examine both the skewness and maximum past returns of the stocks in each of our 25 portfolios constructed above. While high-IVOL stocks have both higher positive skewness and larger maximum past returns as compared to low-IVOL stocks, consistent with results in the above studies, these differences between high- and low-IVOL stocks are very similar among both overpriced and underpriced stocks. Thus, these studies' explanations are challenged by the switch in sign of the IVOL effect as a function of mispricing. Also challenged by that switch in sign is the explanation proposed by Jiang, Xu, and Yao (2009), who argue that high IVOL is associated with firms that disclose less, and that the market does not correctly assess the negative valuation implication associated with selective low disclosure. Similarly, Rachwalski and Wen (2012) conclude that the negative relation between recent IVOL and expected return reflects a positive underlying price of IVOL combined with underreaction by investors to recent IVOL innovations. That argument is consistent with the overall negative IVOL effect but seems challenged by the positive IVOL effect among underpriced stocks.

An alternative explanation consistent with standard asset pricing theory is that the IVOL effect reflects compensation for an omitted systematic risk factor. Barinov (2013) and Chen and Petkova (2012) conclude that IVOL proxies for sensitivity to a priced volatility factor, but this explanation also has a problem accommodating the switch in sign of the IVOL effect. If IVOL is correlated in the cross-section with the sensitivity to a systematic factor, and that factor has a negative premium, then such a scenario is consistent with the negative 
IVOL effect among overpriced stocks but not with the positive relation among underpriced stocks. Indeed, as we report in the on-line appendix, if we use our 25 portfolios to estimate the sensitivities to average-correlation and average-variance factors, as defined in Chen and Petkova (2012), the second-stage cross-sectional regressions produce coefficient estimates with opposite signs to what that study obtains.

A more general factor-based scenario is that alphas are proportional to sensitivities to a missing risk factor. Positive alphas would then be positively related in the cross-section to the return variance attributable to the missing factor, and negative alphas would exhibit a negative relation to that variance component. If the variances attributable to the missing factor are then significant portions of the variances that we identify as idiosyncratic when using just the three Fama-French ( FF) factors, the signs of the IVOL effects we observe would result. To explore this alternative explanation empirically, we construct a factor consisting of the long-short daily return spread between stocks in the top and bottom quintiles of our mispricing measure. Essentially by construction, stocks with high (low) alphas have high (low) sensitivities to this factor. If we then compute IVOLs using a model including this factor in addition to the FF factors, the resulting IVOLs have an average rank correlation of 99.7\% with the IVOLs based on just the FF factors. In other words, our IVOL rankings are virtually unchanged if we remove from IVOL the variance attributable to this alpha-based factor. While this factor does not exhaust the set of omitted factors for which sensitivities might be highly correlated with alphas, we suggest it does reduce the plausibility of such a scenario's explaining the IVOL effects in expected returns. In addition, the asymmetry in the strengths of the positive and negative IVOL effects we observe would still seem to present a challenge for such an alternative explanation.

As explained earlier, a stock's mispricing measure in a given month is constructed by equally weighting the stock's percentile rankings for each of 11 anomalies. Equal weights across the 11 anomalies are simple and transparent but not crucial for our results. We obtain results very similar to those in Table II when applying weights that are instead proportional to rolling five-year averages of the coefficients in a cross-sectional regression of monthly benchmark-adjusted returns on anomaly rankings. ${ }^{12}$ Rather than regressing returns on all 11 individual anomaly rankings, we first group anomalies into five clusters, equally weighting the rankings within each cluster. As compared to weights produced by regressing on the individual rankings, the regression-based weights on each cluster are substantially more stable over time and are rarely negative. (Three anomalies-Financial Distress, Oscore Bankruptcy Probability, and Investment-to-Assets - often receive negative weights in a regression on the 11 individual anomalies.) The clusters are formed using the same procedure 
as Ahn, Conrad, and Dittmar (2009), who combine a correlation-based distance measure with the clustering method of Ward (1963). We apply this procedure using the correlation matrix of benchmark-adjusted returns on the 11 anomalies, as reported in Stambaugh, Yu, and Yuan (2012). The results corresponding to those in Table II are included in the online appendix.

\section{B. Estimating the Role of Mispricing}

Our empirical analysis thus far is based on portfolio sorts, so it requires only a monotonic relation between the IVOL effect and mispricing. Such an approach is robust to that relation's specific form but reveals less about it as a consequence. In this subsection we use the cross-section of individual stocks to estimate the form of the relation between the IVOL effect and mispricing.

In each month $t$ we estimate a cross-sectional regression of the form,

$$
r_{t+1, i}^{e}=\beta_{0}+f_{t}\left(M_{t, i}\right) \sigma_{t, i}+\epsilon_{t+1, i},
$$

where $r_{t+1, i}^{e}$ is stock $i$ 's excess return in month $t+1$ minus its Fama-French factor adjustment, $M_{t, i}$ is the stock's mispricing proxy (the average of its 11 anomaly ranking percentiles) in month $t$, and $\sigma_{t, i}$ is the stock's IVOL in month $t$. The values of $\sigma_{t, i}$ are standardized each month by subtracting by the cross-sectional mean IVOL within the month and then dividing by the month's cross-sectional standard deviation of IVOL. We estimate $f_{t}(\cdot)$ as a piecewise linear function:

$$
f_{t}(M)=\sum_{k=1}^{n} I\left(\theta_{k-1, t} \leq M<\theta_{k, t}\right) \times\left(a_{k, t}+b_{k, t} M\right),
$$

where

$$
a_{k, t}+b_{k, t} \theta_{k, t}=a_{k+1, t}+b_{k+1, t} \theta_{k, t}, \quad k=1, \ldots, n-1,
$$

$\theta_{0}=0$, and $\theta_{n}=100 \%$. We let $n=15$ and set the $\theta_{k, t}$ 's to equal various percentiles of the cross-sectional distribution of $M_{t, i}$. Our choices are guided by the fact that reliable estimation of the coefficients ( $a_{k, t}$ 's and $b_{k, t}$ 's) requires each segment to contain both a sufficient range of sample $M_{t, k}$ values as well as a sufficiently large sample. In the tails of the distribution, where values of $M_{t, i}$ are relatively more disperse, we set $\theta_{1, t}, \ldots, \theta_{4, t}$ to percentiles 5, 10, 15, and 20, and we set $\theta_{11, t}, \ldots, \theta_{14, t}$ to percentiles $80,85,90$, and 95 . In the middle of the distribution, where values of $M_{t, i}$ are relatively less disperse, we set $\theta_{5, t}, \ldots, \theta_{10, t}$ to percentiles $30,40,50$, 60 , and 70 . 
The function $f_{t}(M)$ in (8) characterizes the relation between the IVOL effect and mispricing. The month-by-month procedure described above yields an estimated function $f_{t}(M)$ for each month $t$ in our sample (August 1965 through January 2011). These monthly values are then used in a procedure following the spirit of Fama and MacBeth (1973). For each value of mispricing $(M)$ in 0.01 increments within [0 1], we take the mean of the monthly function values as an estimate of the desired function, $f(M)=(1 / T) \sum_{t=1}^{T} f_{t}(M)$. We estimate the standard error of $f(M)$ using the monthly series of $f_{t}(M)$ 's.

Figure 3 plots the estimated values of $f(M)$ - the relation between the IVOL effect and mispricing - as well as the 90-percent confidence bands (plus/minus 1.65 standard errors). First note that the estimated IVOL effect is positive among the most underpriced stocks and negative among the most overpriced, consistent with the previous portfolio-sort results. Consistent with those results as well is the asymmetry in the dependence of the IVOL effect on mispricing, with the effect among overpriced stocks reaching larger negative magnitudes than those of the positive effect among underpriced stocks. Also observe that the IVOL effect is more sensitive to $M$ at both extremes of that measure than at the intermediate values. This result makes sense if differences in anomaly rankings percentiles toward the middle of the distribution do not identify economically significant differences in mispricing. It seems reasonable that, if the anomaly rankings identify potential mispricing, they would do so more successfully at the extremes of those rankings.

The estimate of $f(M)$ obtained here explains well the overall IVOL effect obtained when aggregating across all levels of mispricing. If in each month we estimate a simple crosssectional regression of $r_{t+1, i}^{e}$ on $\sigma_{t, i}$ and then average the slope coefficients across all months in the sample, we obtain a value of -0.0030 . That estimate is close to the value of -0.0028 obtained if the estimated values of $f(M)$ plotted in Figure 3 are weighted by the crosssectional sample density of $M$ values. The latter density is obtained by computing the cross-sectional frequency distribution of $M_{t, i}$ each month and then averaging those frequency distributions across months.

One might ask whether a cross-sectional regression can test whether our explanation fully accounts for the IVOL effect. In general, such a test is not possible, in that we do not know a priori the function that relates mispricing to the IVOL effect or even the no-mispricing value for $M_{t, i}$ at which the IVOL effect should flip signs when moving from underpricing to overpricing. The presence of shorting impediments, and thus the resulting net tendency for overpricing, implies that the no-mispricing point should be less than $50 \%$ (closer to the underpriced end), but that is as much as our explanation delivers. Suppose our explanation 
fully accounts for the IVOL effect, and one regresses $r_{t+1, i}^{e}$ on both $\sigma_{t, i}$ and the interaction term $M_{t, i} \sigma_{t, i}$. Then a significantly nonzero coefficient on $\sigma_{t, i}$ would simply indicate that a zero value of $M_{t, i}$ does not correspond to zero mispricing. On the other hand, if each month we instead run a cross-sectional regression of $r_{t+1, i}^{e}$ on both $f\left(M_{t, i}\right) \sigma_{t, i}$ and $\sigma_{t, i}$, the average slope on the latter is -0.00017 with a t-statistic of -0.39 . One should not view the latter insignificance as failure to reject the adequacy of our explanation, however, as $f\left(M_{t, i}\right)$ is fit to the data. The insignificant average slope on $\sigma_{t, i}$ is better viewed as suggesting that $f_{t}(M)$ is typically captured reasonably well by the time-aggregated function $f(M)$.

\section{Institutional Ownership and the IVOL Effect}

Recall from Section I that arbitrage asymmetry at the stock-level also has implications for the IVOL effect. Specifically, among overpriced stocks, the negative IVOL relation should be steeper for stocks less easily shorted. We investigate this implication using data on institutional ownership. Short-sale impediments are likely to be more important among stocks with lower institutional ownership. When institutional ownership is low, stock loan supply tends to be sparse, and thus short selling tends to be more expensive. D'Avolio (2002) finds that lending fees on shorted shares are negatively associated with institutional ownership. Institutional ownership has been used as a proxy for short-sale impedements in many studies, such as Nagel (2005), Duan, Hu, and McLean (2010) and Hirshleifer, Teoh, and $\mathrm{Yu}(2011)$ ). Nagel (2005) finds, for example, that various return anomalies are stronger among stocks with low IO, consistent with the importance of stock-level arbitrage asymmetry and the ability of IO to proxy for that asymmetry. ${ }^{13}$ Since IO is positively correlated with firm size, we follow Nagel and compute size-adjusted IO, which is the residual in a cross-sectional regression that fits the logit of IO (in percent) as a quadratic function of the logarithm of firm size. Our data on institutional holdings are obtained from Thomson Financial Institutional Holdings and run from 4/1980 through 1/2011.

To investigate the implications of stock-level arbitrage asymmetry, we conduct a threeway sort. First, we assign stocks to mispricing quintiles by sorting on our mispricing measure. Within each mispricing quintile, we then sort by IVOL, forming five groups, and independently by IO, forming three groups. Table III reports, for each mispricing quintile, the average benchmark-adjusted returns for the "corner" portfolios of the IVOL-IO double sort.

The last row reports results based on the double sort within the entire stock universe.

[Table

III]

Within a given mispricing quintile, the independent sorting produces very similar ranges 
of IVOL across the different IO groupings, thereby allowing us to examine differences in the strength of the IVOL effect across different IO levels. For example, within the most

overpriced stocks - those of greatest interest in exploring the effects of stock-level arbitrage asymmetry - the high and low IVOL values for the high-IO group are $5.12 \%$ and $0.37 \%$, while the corresponding values in the low-IO group are $5.25 \%$ and $0.33 \%$.

Stock-level arbitrage asymmetry predicts that the negative IVOL effect among overpriced stocks should be stronger for stocks less easily shorted. This prediction is supported by the first row of Table III, which reports results for the most overpriced stocks. Among low-IO stocks (those less easily shorted), the difference in average monthly returns between the portfolios with high and low IVOL is $-2.95 \%$, while the corresponding difference for highIO stocks is $-2.03 \%$. This economically significant difference in IVOL effects of 92 basis points per month has a t-statistic of -1.94 , yielding a p-value of 0.026 for a test of the zerodifference null against the one-sided alternative hypothesis implied by stock-level arbitrage asymmetry.

Stock-level arbitrage asymmetry should play less of a role in the IVOL effect among stocks that are less overpriced, and we see that pattern in Table III. Among stocks in the secondhighest mispricing quintile, the negative IVOL effect for low-IO stocks is again stronger than that for high-IO stocks, but the difference of 52 basis points and its associated p-value of 0.099 correspond to less economic and statistical significance than observed among the most overpriced stocks. Among the remaining three mispricing quintiles, the differences in IVOL effects between the two IO groups are relatively small and statistically insignificant, consistent with the implication that stock-level arbitrage asymmetry should matter only among overpriced stocks.

Nagel (2005) observes that within the overall stock universe, the negative IVOL effect is stronger for firms with low IO. The last row of Table III reveals a similar result, in that the average IVOL effect among firms with low IO exceeds the average IVOL effect among firms with high IO by a difference of 0.38 percent, and the t-statistic of 1.49 yields a p-value of 0.068 against the one-sided alternative. Our results reveal that this IO-related difference in the IVOL effect within the overall stock universe is attributable to the overpriced stocks, as implied by stock-level arbitrage asymmetry.

\section{Time-Varying IVOL Effects}

In our setting, the IVOL effect in expected return hinges on mispricing. Recall that our 
mispricing measure at best identifies only relative mispricing. Periods when overpricing in the stock market is more likely in general are also those times when our relatively overpriced stocks are more likely to be overpriced in absolute terms and our underpriced stocks are less likely to be underpriced in absolute terms. At such times, the negative IVOL effect among our "overpriced" stocks should be stronger, and the positive IVOL effect among our "underpriced" stocks should be weaker. In the context of equations (5) and (6), if potential mispricing in a stock occurs due to excess noise-trader demand, $y_{i}$, then systematic variation over time in the typical values of $y_{i}$ across stocks should produce variation in the strength of the corresponding IVOL effects.

To investigate such time-varying IVOL effects, we need to identify variation over time in the general tendency for overpricing versus underpricing in the stock market. For this purpose, we rely on the index of market-wide investor sentiment constructed by Baker and Wurgler (2006). Their index is constructed as the first principal component of six underlying measures of investor sentiment: the average closed-end fund discount, the number and the first-day returns of IPO's, NYSE turnover, the equity share of total new issues, and the dividend premium (log difference of average market/book of dividend payers vs. nonpayers). Those authors show that their sentiment index predicts returns on stocks more likely to be susceptible to mispricing, such as stocks on small or young firms, more volatile stocks, distressed stocks, and extreme growth stocks. Further evidence that the Baker-Wurgler (BW) index identifies variation in mispricing is provided by Stambaugh, Yu, and Yuan (2012), who find that the index significantly predicts long-short return spreads for each of the same 11 anomalies we analyze here.

Stambaugh, Yu, and Yuan (2012) also find that the ability of sentiment to predict the long-short return spreads is due largely to predictability of the short-leg returns. As those authors explain, the latter result is predicted by arbitrage asymmetry in a setting in which sentiment-driven noise traders have strongly positive demands for many stocks when sentiment is high but do not have correspondingly negative demands when sentiment is low, due to an inability or reluctance to sell short. In the context of equations (5) and (6), this asymmetric effect of market-wide sentiment on noise trader demands is equivalent to sentiment's having greater effects on the low $y_{i}$ 's that produce overpricing than on the high $y_{i}$ 's that produce underpricing. When applied to our analysis of IVOL effects, this asymmetry implies that investor sentiment should exert a greater effect on the negative IVOL effect among overpriced stocks than on the positive IVOL effect among underpriced stocks.

The first subsection below investigates whether IVOL effects vary over time with investor 
sentiment in the ways discussed above. The results indicate that they do. For this initial investigation of sentiment effects, we use the "raw" version of the BW index from which macroeconomic effects are not removed. The reason for doing so is that investor sentiment could be related to macroeconomic factors. For example, when the economy is doing well, investors could also be more optimistic, and thus more likely to push prices above fundamental values. While such macro-related sentiment effects are perfectly consistent with our setting, many readers might ask whether they play a role in our results. In the second subsection below, we investigate this question by using Baker and Wurgler's (2006) alternative sentiment measure, which removes the effects of six macro variables. We further include six additional macro variables that previous empirical studies relate to expected stock returns. Our results point to little or no role for macro factors in the sentiment-related variation in the IVOL effects that we observe.

\section{A. Investor Sentiment and IVOL Effects}

To explore the sentiment-related implications discussed above, we first conduct a sortingbased portfolio analysis, similar to that in Table II, separately for high-sentiment and lowsentiment months. We modify the sorting procedure somewhat due to the shift in focus from the cross-section to the time-series when investigating IVOL effects. In order to compare IVOL effects across time for a given level of mispricing, one would ideally maintain the same volatility breakpoints across different periods. Doing so, however, confronts the fact that average IVOL levels fluctuate substantially through time (e.g., Brandt, Brav, Graham, and Kumar, 2010). Maintaining fixed IVOL breakpoints in the portfolio sorting is therefore not feasible, as it results in highly unbalanced distributions of stocks in many periods, often producing portfolios with few or no stocks. Therefore, for each mispricing level, we instead set fixed percentage breakpoints for IVOL, forming five portfolios each period with essentially equal numbers of stocks in each portfolio. In addition to presenting results based on this portfolio-based analysis, we also redo the individual-stock-based estimation in Subsection III.B separately in high-sentiment and low-sentiment months.

Table IV presents the results of the portfolio-based analysis of the IVOL effect following different levels of investor sentiment. The middle three IVOL categories are omitted to save space in the table. Average benchnark-adjusted returns for all five IVOL categories in lowsentiment and high-sentiment months are displayed in Figure 4. A high-sentiment month is one in which the value of the BW sentiment index at the end of the previous month is above the median value for the 1965:8-2011:1 sample period, while the low-sentiment months are 
those with below-median index values in the previous month.

The results in Table IV and Figure 4 are consistent with the hypothesized sentimentrelated variation in the IVOL effect discussed earlier. First observe that among all stocks (bottom row), the negative IVOL effect is significantly stronger following high sentiment, as predicted. The spread between the highest-IVOL and lowest-IVOL average returns is $-1.32 \%$ following high sentiment compared to $-0.23 \%$ following low sentiment - a difference of $-1.09 \%$ (t-statistic: -3.82 ). This sentiment-related variation in the overall IVOL effect is similar to a result in Baker and Wurgler (2006), who use lagged within-year standard deviation of monthly total return, instead of IVOL. Our analysis, which investigates IVOL effects separately within different degrees of relative mispricing, reveals that the IVOL effect within the relatively overpriced stocks exhibits the same sentiment-related variation as does the overall IVOL effect. Among the most overpriced stocks, the spread between the highest-IVOL and lowest-IVOL average returns is $-2.30 \%$ following high sentiment compared to $-1.30 \%$ following low sentiment - a difference of $-1.00 \%$ (t-statistic: -2.29 ). For the most underpriced stocks, the positive IVOL effect is stronger following low sentiment than following high sentiment: Among those stocks, the spread between the highest-IVOL and lowest-IVOL average returns is $0.21 \%$ following high sentiment compared to $0.94 \%$ following low sentiment - a difference of $-0.73 \%$ (t-statistic: -2.03 ). These results go in the direction of supporting arbitrage asymmetry as well, in that the sentiment-related difference in IVOL effects is somewhat larger for the most overpriced stocks, although the t-statistic for the difference is modest $(-0.53)$. When interpreting this last result, one should probably consider that a binary split between high- and low-sentiment periods, while useful in its simplicity, does not necessarily yield the most powerful test. Below we also estimate time-series regressions as an alternative approach.

The binary split between high and low sentiment does also allow us to explore the effect of sentiment on the function $f(M)$ that characterizes the role of mispricing in the IVOL effect. To do so, we repeat the estimation described in subsection III.B, except that we average the values of $f_{t}(M)$ separately over high- and low-sentiment months. Figure 5 displays the resulting estimates of $f(M)$ in the two subsamples. Consistent with the above portfolio results, the negative IVOL effect in overpriced stocks is stronger following high sentiment, and the positive IVOL effect among underpriced stocks is stronger following low sentiment. The t-statistics for the differences between the two curves exceed -2.0 in magnitude for values of $M$ between $20 \%$ to $30 \%$ (underpricing) as well as between $70 \%$ and $80 \%$ (overpricing). As $M$ takes more extreme values at both ends, the t-statistics decline in magnitude to about -1.0 , consistent with there being fewer observations in the tails and thus less precision in 
the estimates of $f(M)$. We also see that sentiment exerts little if any effect on the relation between the IVOL effect and $M$ for intermediate values of $M$, which is consistent with there being minimal mispricing at such values.

Table $\mathrm{V}$ reports the results of regressing excess returns or return spreads in month $t$ on the variable $S_{t-1}$, the level of the BW index at the end of the previous month. Also included as independent variables are the contemporaneous realizations of the Fama-French factors (MKT, SMB, and HML), so the slope on $S_{t-1}$ reflects sentiment-related variation in the benchmark-adjusted returns. The dependent variable in the regressions is either (i) the (excess) return on the highest-IVOL portfolio, (ii) the return on the lowest-IVOL portfolio, or (iii) the difference between those returns. These three regressions are run separately within each mispricing category and within the overall stock universe.

The results in Table $\mathrm{V}$ are again supportive of our setting's implications. Consistent with Table IV, the IVOL effect (highest minus lowest IVOL) is negatively related to investor sentiment. Within the overall stock universe, the slope on $S_{t-1}$ is equal to -0.66 (t-statistic: -4.25), meaning that a one-standard-deviation swing in $S_{t-1}$ is associated with a 66-basispoint difference in the IVOL effect. In addition, that negative slope is largest in magnitude among the most overpriced stocks, and the difference between the slopes for the most overpriced versus the most underpriced stocks is equal to -0.50 (t-statistic: -2.20 ).

Our use of the BW index as an independent variable in time-series regressions follows, for example, Baker and Wurgler (2006) and Stambaugh, Yu, and Yuan (2012). One potential concern in any time-series regression is that a seemingly significant relation is spurious. This concern looms larger, the weaker is the prior motivation for the independent variable. Investor sentiment has long been entertained as exerting a significant influence on stock prices (e.g., Keynes, 1936), but spurious-regressor concerns can nevertheless arise. Indeed such a concern with regard to investor sentiment is raised by Novy-Marx (2014). Simulations reported by Stambaugh, Yu, and Yuan (2014) reveal that the spurious regressor concern is greatly diminished when considering the ability of such a regressor to generate predicted results simultaneously across a number of regressions.

\section{B. Exploring macroeconomic effects}

As mentioned earlier, investor sentiment could be related to macroeconomic factors. It is quite possible, for example, that when macroeconomic conditions are especially good, some investors also become too optimistic and push equity prices above levels justified by funda- 
mental values. Similarly, during recessions, some investors could become too pessimistic and undervalue stocks as a result. As long as high (low) sentiment makes overpricing (underpricing) more likely, the extent to which sentiment relates to the macroeconomy does not affect the implications explored above. Nevertheless, the extent to which macroeconomic conditions play a role in our results are of potential interest.

Baker and Wurgler (2006) construct an alternative sentiment index that removes macrorelated variation by regressing their raw sentiment measures on six macro variables: the growth in industrial production, the growth in durable, nondurable, and services consumption, the growth in employment, and a flag for NBER recessions. Panel A of Table VI repeats the regressions in Table $\mathrm{V}$ using this alternative sentiment index. The results are very similar to those in Table $\mathrm{V}$, indicating no important role for the six Baker-Wurgler [Table macro variables in the former results. In Panel B of Table VI, we repeat the regression in Panel A but add six additional macro-related independent variables: the default premium, the term premium, the real interest rate, the inflation rate, the consumption surplus ratio, and CAY. These variables are often identified as being related to expected stock returns, so they seem especially relevant for exploring the role of macroeconomic conditions in our results. The default premium is defined as the yield spread between BAA and AAA bonds, and the term premium is defined as the spread between 20-year and 1-year Treasuries. The real interest rate is defined as the most recent monthly difference between the 30-day T-bill return and the CPI inflation rate. The consumption surplus ratio defined in Campbell and Cochrane (1999). Cay is the consumption-wealth variable defined in Lettau and Ludvigson (2001). ${ }^{14}$ The conclusions summarized previously based on Table V are again essentially unchanged if instead based Panel B of Table VI. Overall, the results in Table VI indicate that the sentiment-related variation in the IVOL effect admits little or no role for the macro variables included in our investigation.

We do not include macro variables directly related to the stock market, such as dividend yield. In this sense, our choice of macro variables differs from that of Sibley, Xing, and Zhang (2012). Those authors investigate whether it is macro-related sentiment or non-macro-related sentiment that displays the ability to predict anomaly returns, as documented in Stambaugh, Yu, and Yuan (2012). Sibley, Xing, and Zhang conclude that it is largely macro-related sentiment that exhibits the predictive ability. Such a result is consistent with sentimentdriven mispricing in any event, but the distinction between macro and non-macro effects seems less interesting when the macro variables include stock-market variables. Sentiment that affects stock prices is likely to affect dividend yield, lowering yield when sentiment is high, and vice versa. One would expect a sentiment measure purged of those stock-price 
effects to be less effective in identifying sentiment-driven stock mispricing and, therefore, to be less effective in predicting anomaly returns that reflect such mispricing. ${ }^{15}$

\section{Excluding Smaller Firms}

It is well known that smaller firms tend to have higher IVOL, and we also find that firm size tends to decline as our mispricing measure increases (i.e., as the measure moves from underpriced to overpriced). The fact that size is related to both IVOL and our mispricing measure raises the question of whether our results hinge importantly on including small firms. Our use of value-weighted portfolios in the previous results reduces this possibility, but in this section we go further and explore the sensitivity of our results to excluding firms below a given size threshold.

Table VII repeats the analysis reported earlier in Table II but with smaller firms excluded. Before performing the two-way sort on IVOL and the mispricing measure, we eliminate all firms whose equity capitalization falls in the bottom $p$ percent of the stock universe, for various choices of $p$. Specifically, in Panels A, B, C, and D, of Table VII, we exclude the bottom 20 percent, 40 percent, 60 percent, and 80 percent, respectively. First observe from Table II and Table VII that the overall negative relation between IVOL and average return progressively weakens as the size threshold increases, but even among the largest quintile of stocks (Panel D) the average monthly spread between the high- and low-IVOL portfolios is still -0.26 percent (t-statistic: -1.88 ). This result is consistent with the results in Ang, Hodrick, Xing, and Zhang (2006), who find that the IVOL puzzle exists within all size quintiles but is weaker for larger firms.

The key result for the purpose of this study is that, as the size threshold increases, the IVOL effect continues to display the same dependence on the direction and degree of mispricing as observed earlier in Table II. That is, the IVOL effect is significantly negative (positive) among the most overpriced (underpriced) stocks, but the negative effect is significantly stronger. We do observe that the latter asymmetry weakens somewhat as the size threshold increases, which is consistent with the corresponding weakening of the overall IVOL effect. Even for the largest stocks (Panel D), however, the negative IVOL effect among the most overpriced stocks ( -0.77 percent, t-statistic: -3.66$)$ exceeds the positive IVOL effect among the most underpriced stocks (0.47 percent, t-statistic: 2.34$)$ by a difference of -1.23 percent (t-statistic: -4.82$)$.

We can see that the weakening of the asymmetry in the IVOL effect as the size threshold 
increases comes primarily from the weakening of the negative IVOL effect among the overpriced stocks. For the portfolio of the most overpriced stocks, the IVOL effect starting in Table II and then progressing through the four panels of Table VII takes the values -1.50, $-1.31,-1.05,-1.02$, and -0.77 , which display a clear increasing pattern. Among the most underpriced stocks, the comparable values are $0.41,0.31,0.39,0.40$, and 0.47 , which display little or no pattern. In other words, as progressively larger stocks are eliminated, the positive IVOL effect among the most underpriced stocks remains fairly stable in magnitude, whereas the negative IVOL effect among the most overpriced stocks weakens. These patterns are consistent with the simple model presented earlier, given that small-firm stocks are likely to be less easily shorted. Recall that, among overpriced stocks, the model implies that the relation between alpha and IVOL is steeper among the stocks less easily shorted. In contrast, differences in shorting difficulty have no effect on the steepness of the relation for underpriced stocks.

Finally, we repeat the analysis in Table $\mathrm{V}$ under the same progressive elimination of smaller firms employed in Table VII, and the results are reported in Table VIII. In all four panels of Table VIII, the IVOL effect among overpriced stocks exhibits a significantly [Table negative relation to investor sentiment, with magnitudes ranging from -0.79 to -0.91 , comparable to the value of -0.79 in Table $\mathrm{V}$. The IVOL effect among underpriced stocks exhibits a consistently weaker negative relation to sentiment, again as in Table V. We do see that excluding smaller firms causes the t-statistics for those negative coefficients to drop below conventional significance levels. Finding a weaker negative relation among the underpriced stocks is consistent with arbitrage asymmetry, as discussed earlier.

\section{Conclusions}

We provide an explanation for the negative empirical relation between expected return and idiosyncratic volatility (IVOL) observed in the overall cross section of equities. Our explanation combines two simple concepts. The first is that higher IVOL, which translates to higher arbitrage risk, allows greater mispricing. As a result, expected return is negatively (positively) related to IVOL among overpriced (underpriced) securities. The second concept is that arbitrage is asymmetric, in that short sellers face greater impediments than purchasers.

Arbitrage asymmetry exists at both the investor level and the stock level. Some investors are more able or willing to short than are other investors, and some stocks are more easily 
shorted than are other stocks. Our simple model incorporates both dimensions of arbitrage asymmetry, and it captures the basic intuition that when arbitrage risk is shared by less capital, less mispricing is eliminated in equilibrium.

The combined effects of arbitrage risk and arbitrage asymmetry imply that a given difference in IVOL is associated with a greater average degree of overpricing as compared to underpricing. That is, the negative IVOL effect among overpriced stocks is stronger than the positive effect among underpriced stocks, and thus a negative IVOL effect emerges within the overall cross section. In addition, among the overpriced stocks, the negative IVOL effect is steeper for stocks less easily shorted.

Our empirical evidence supports these implications. First, using a composite measure based on 11 return anomalies to gauge relative mispricing, we find a significant positive IVOL effect among the most underpriced stocks but a stronger negative effect among the most overpriced ones. We also find that the negative IVOL effect among overpriced stocks is stronger for stocks less easily shorted, as proxied by having low size-adjusted institutional ownership.

We also empirically confirm time-series implications of our explanation. Using investor sentiment as a proxy for the likely direction of market-wide mispricing, we find that the negative (positive) IVOL effect among overpriced (underpriced) stocks is stronger when market-wide overpricing (underpricing) is more likely. This negative relation over time between investor sentiment and the return difference between high- and low-volatility portfolios is stronger among overpriced stocks, consistent with the presence of arbitrage asymmetry. Finally, mispricing's role in the IVOL effect, in both the cross-section and time series, is robust to eliminating smaller firms. 


\section{Appendix}

\section{Derivation of equations (5) and (6)}

The investors in group $I_{M}$ face the constraint that the elements of $\omega$ must be non-negative for the last $N_{2} \equiv N-N_{1}$ stocks, whereas the investors in group $I_{H}$ face no constraint on $\omega$. The first-order condition for an investor in group $I_{M}$ is given by

$$
\mu-A V \omega_{M}-\lambda=0,
$$

where the first $N_{1}$ elements of $\lambda$ are zero and the last $N_{2}$ elements of $\lambda$ are the vector of Lagrange multipliers associated with the non-negativity constraints on the last $N_{2}$ elements of $\omega$. We order the stocks such that they can be partitioned into two groups. The first group includes the first $N_{1}$ (unconstrained) stocks and stocks numbered $N_{1}+1$ to $N_{1}+N_{n c}$ in which investors in group $I_{M}$ hold positive allocations. In the second group of stocks, the constraints result in zero allocations for investors in group $I_{M}$. Here, $N_{n c}$ is the number of stocks among the last $N_{2}$ stocks where the short-sale constraint is not binding for investors in group $I_{M}$. Rewriting (A1) with this partitioning gives,

$$
\left[\begin{array}{l}
\mu_{1} \\
\mu_{2}
\end{array}\right]-A\left[\begin{array}{ll}
V_{11} & V_{12} \\
V_{21} & V_{22}
\end{array}\right]\left[\begin{array}{c}
\omega_{M, 1} \\
0
\end{array}\right]-\left[\begin{array}{c}
0 \\
\lambda_{2}
\end{array}\right]=\left[\begin{array}{l}
0 \\
0
\end{array}\right],
$$

noting that $\lambda_{1}=0$ and $\omega_{M, 2}=0$. From (A2) we obtain the optimal positive allocations for investors in group $I_{M}$ as

$$
\omega_{M, 1}=\frac{1}{A} V_{11}^{-1} \mu_{1} .
$$

The first-order condition for investors in group $I_{H}$ gives their optimal allocations as

$$
\omega_{H}=\frac{1}{A} V^{-1} \mu .
$$

Market clearing requires

$$
M \omega_{M}+H \omega_{H}=y,
$$

or

$$
\left[\begin{array}{c}
\frac{M}{A} V_{11}^{-1} \mu_{1} \\
0
\end{array}\right]+\frac{H}{A} V^{-1} \mu=y .
$$

Multiplying both sides of (A6) by $V$ gives

$$
\left[\begin{array}{c}
\frac{M}{A} \mu_{1} \\
\frac{M}{A} V_{21} V_{11}^{-1} \mu_{1}
\end{array}\right]+\left[\begin{array}{c}
\frac{H}{A} \mu_{1} \\
\frac{H}{A} \mu_{2}
\end{array}\right]=\left[\begin{array}{c}
V_{11} y_{1}+V_{12} y_{2} \\
V_{21} y_{1}+V_{22} y_{2}
\end{array}\right] .
$$


From (A7) we obtain the equilibrium expected excess returns as

$$
\begin{aligned}
\mu_{1} & =\frac{A}{M+H}\left(V_{11} y_{1}+V_{12} y_{2}\right) \\
\mu_{2} & =\frac{A}{H}\left(V_{21} y_{1}+V_{22} y_{2}-\frac{M}{A} V_{21} V_{11}^{-1} \mu_{1}\right) \\
& =\frac{A}{H}\left(V_{21} y_{1}+V_{22} y_{2}-\frac{M}{A} V_{21} V_{11}^{-1}\left[\frac{A}{M+H}\left(V_{11} y_{1}+V_{12} y_{2}\right)\right]\right) \\
& =\frac{A}{H}\left(V_{22}-\frac{M}{M+H} V_{21} V_{11}^{-1} V_{12}\right) y_{2}+\frac{A}{M+H} V_{21} y_{1} .
\end{aligned}
$$

The partitioning of $V$ in (A2) can also be expressed as

$$
V=\left[\begin{array}{ll}
V_{11} & V_{12} \\
V_{21} & V_{22}
\end{array}\right]=\left[\begin{array}{cc}
\sigma_{m}^{2} \beta_{1} \beta_{1}^{\prime}+\Sigma_{11} & \sigma_{m}^{2} \beta_{1} \beta_{2}^{\prime} \\
\sigma_{m}^{2} \beta_{2} \beta_{1}^{\prime} & \sigma_{m}^{2} \beta_{2} \beta_{2}^{\prime}+\Sigma_{22}
\end{array}\right] .
$$

We then have

$$
\begin{aligned}
\mu_{1} & =\frac{A}{M+H}\left[\left(\sigma_{m}^{2} \beta_{1} \beta_{1}^{\prime}+\Sigma_{11}\right) y_{1}+\sigma_{m}^{2} \beta_{1} \beta_{2}^{\prime} y_{2}\right] \\
& =\frac{A}{M+H} \Sigma_{11} y_{1}+\beta_{1}\left(\frac{\sigma_{m}^{2} A}{M+H}\right) \beta^{\prime} y,
\end{aligned}
$$

and

$$
\begin{aligned}
\mu_{2}= & \frac{A}{H}\left(\sigma_{m}^{2} \beta_{2} \beta_{2}^{\prime}+\Sigma_{22}-\frac{M \sigma_{m}^{4}}{M+H} \beta_{2} \beta_{1}^{\prime}\left[V_{11}^{-1}\right] \beta_{1} \beta_{2}^{\prime}\right) y_{2}+\frac{A \sigma_{m}^{2}}{M+H} \beta_{2} \beta_{1}^{\prime} y_{1} \\
= & \frac{A}{H}\left(\sigma_{m}^{2} \beta_{2} \beta_{2}^{\prime}+\Sigma_{22}-\frac{M \sigma_{m}^{4}}{M+H} \beta_{2} \beta_{1}^{\prime}\left[\Sigma_{11}^{-1}-\frac{\sigma_{m}^{2}}{1+\sigma_{m}^{2} \beta_{1}^{\prime} \Sigma_{11}^{-1} \beta_{1}} \Sigma_{11}^{-1} \beta_{1} \beta_{1}^{\prime} \Sigma_{11}^{-1}\right] \beta_{1} \beta_{2}^{\prime}\right) y_{2} \\
& +\frac{A \sigma_{m}^{2}}{M+H} \beta_{2} \beta_{1}^{\prime} y_{1} \\
= & \frac{A}{H}\left(\sigma_{m}^{2} \beta_{2} \beta_{2}^{\prime}+\Sigma_{22}-\frac{M \sigma_{m}^{2}}{M+H}\left[\frac{\sigma_{m}^{2} \beta_{1}^{\prime} \Sigma_{11}^{-1} \beta_{1}}{1+\sigma_{m}^{2} \beta_{1}^{\prime} \Sigma_{11}^{-1} \beta_{1}}\right] \beta_{2} \beta_{2}^{\prime}\right) y_{2}+\frac{A \sigma_{m}^{2}}{M+H} \beta_{2} \beta_{1}^{\prime} y_{1} \\
= & \frac{A}{H} \Sigma_{22} y_{2}+\beta_{2} \frac{A \sigma_{m}^{2}}{H}\left(1-\frac{M}{M+H}\left[\frac{\sigma_{m}^{2} \beta_{1}^{\prime} \Sigma_{11}^{-1} \beta_{1}}{1+\sigma_{m}^{2} \beta_{1}^{\prime} \Sigma_{11}^{-1} \beta_{1}}\right]\right) \beta_{2}^{\prime} y_{2}+\frac{A \sigma_{m}^{2}}{M+H} \beta_{2} \beta_{1}^{\prime} y_{1} \\
= & \frac{A}{H} \Sigma_{22} y_{2}+\beta_{2}\left(\frac{A \sigma_{m}^{2}}{H}\left[1-\frac{M}{M+H}\left(\frac{\sigma_{m}^{2} \beta_{1}^{\prime} \Sigma_{11}^{-1} \beta_{1}}{1+\sigma_{m}^{2} \beta_{1}^{\prime} \Sigma_{11}^{-1} \beta_{1}}\right)\right] \beta_{2}^{\prime} y_{2}+\frac{A \sigma_{m}^{2}}{M+H} \beta_{1}^{\prime} y_{1}\right) .(\mathrm{A} 13)
\end{aligned}
$$

Let $\mu_{m}$ denote the expected excess return on the market portfolio. Then from (A11), we have that for each asset $i$ in the first group of stocks (i.e., the first $N_{1}+N_{n c}$ stocks) for which the constraint is not binding for investors in group $I_{M}$,

$$
\alpha_{i}=\frac{A}{M+H} y_{i} \sigma_{\epsilon, i}^{2}+\delta \beta_{i},
$$


where

$$
\delta=\left(\frac{\sigma_{m}^{2} A}{M+H}\right) \beta^{\prime} y-\mu_{m}
$$

From (A13), we have that for each asset $i$ in the second group of stocks for which investors in group $I_{M}$ hold a zero allocation,

$$
\alpha_{i}=\frac{A}{H} y_{i} \sigma_{\epsilon, i}^{2}+\psi \beta_{i},
$$

where

$$
\psi=\frac{A \sigma_{m}^{2}}{H}\left[1-\frac{M}{M+H}\left(\frac{\sigma_{m}^{2} \beta_{1}^{\prime} \Sigma_{11}^{-1} \beta_{1}}{1+\sigma_{m}^{2} \beta_{1}^{\prime} \Sigma_{11}^{-1} \beta_{1}}\right)\right] \beta_{2}^{\prime} y_{2}+\frac{A \sigma_{m}^{2}}{M+H} \beta_{1}^{\prime} y_{1}-\mu_{m} .
$$

As the number of assets $(N)$ grows large (and thus as $N_{1}+N_{n c}$ grows large), observe that

$$
\left(\frac{\sigma_{m}^{2} \beta_{1}^{\prime} \Sigma_{11}^{-1} \beta_{1}}{1+\sigma_{m}^{2} \beta_{1}^{\prime} \Sigma_{11}^{-1} \beta_{1}}\right) \rightarrow 1
$$

since $\beta_{1}^{\prime} \Sigma_{11}^{-1} \beta_{1}=\sum_{i=1}^{N_{1}+N_{n c}} \beta_{i}^{2} / \sigma_{\epsilon, i}^{2}$. Therefore, as $N$ grows large,

$$
\psi \rightarrow \frac{A \sigma_{m}^{2}}{M+H}\left(\beta_{1}^{\prime} y_{1}+\beta_{2}^{\prime} y_{2}\right)-\mu_{m}=\left(\frac{\sigma_{m}^{2} A}{M+H}\right) \beta^{\prime} y-\mu_{m}=\delta .
$$

Finally, we will show that $\delta=0$ under the assumptions,

(C1) noise traders do not cause the equity premium to differ from what it would otherwise be,

(C2) the equally weighted average beta equals one,

(C3) noise trader demands, $z$, are uncorrelated with betas in the cross section.

If $z=0$, then $\delta=0$. To see this, first note that, by definition, the market-capitalizationweighted average of the betas is equal to one,

$$
\frac{1}{\iota^{\prime} s} \beta^{\prime} s=1,
$$

and thus in general, $\beta^{\prime} s=S$, where $S=\iota^{\prime} s$ is the total market capitalization of all assets. With no noise-trader demands, $S(1-q)=M+H$, and thus

$$
\begin{aligned}
\delta & =\left(\frac{\sigma_{m}^{2} A}{M+H}\right) \beta^{\prime} y-\mu_{m} \\
& =\left(\frac{\sigma_{m}^{2} A}{M+H}\right) \beta^{\prime} s(1-q)-\mu_{m} \\
& =\left(\frac{\sigma_{m}^{2} A}{M+H}\right)(M+H)-\mu_{m} . \\
& =\sigma_{m}^{2} A-\mu_{m} .
\end{aligned}
$$


In addition, with $z=0$, note that non-negativity constraints on investors in group $I_{M}$ would not bind: If both investors in group $I_{M}$ and group $I_{H}$ have demands given by the unconstrained MV-optimal portfolio, allocations in that portfolio must all be positive - equal to market-portfolio allocations. With market allocations equal to the unconstrained solution $\omega_{H}$ in (A4), multiplying both sides of that equation by $\omega_{H}^{\prime} V$ gives $\omega_{H}^{\prime} V \omega_{H}=\sigma_{m}^{2}=\frac{1}{A} \mu_{m}$, and thus the last line in (A20) is equal to zero.

If $z \neq 0$, then rewrite $(\mathrm{A} 15)$ as

$$
\begin{aligned}
\delta & =\left(\frac{\sigma_{m}^{2} A}{M+H}\right)\left(\beta^{\prime} s(1-q)-\beta^{\prime} z\right)-\mu_{m} \\
& =\left(\frac{\sigma_{m}^{2} A}{M+H}\right)\left(S(1-q)-\beta^{\prime} z\right)-\mu_{m} \\
& =\left(\frac{\sigma_{m}^{2} A}{M+H}\right)\left(M+H+\iota^{\prime} z-\beta^{\prime} z\right)-\mu_{m} \\
& =\sigma_{m}^{2} A-\mu_{m}-\left(\frac{\sigma_{m}^{2} A}{M+H}\right)(\beta-\iota)^{\prime} z .
\end{aligned}
$$

The first two terms combine to zero under $(\mathrm{C} 1)$, and the third term equals zero because $(\mathrm{C} 2)$ and (C3) imply $(\beta-\iota)^{\prime} z$, so again $\delta=0$.

\section{Anomalies}

Financial Distress ( $\left.\begin{array}{lll}1 & 8 & 2\end{array}\right)$ : Financial distress is often invoked to explain otherwise anomalous patterns in the cross-section of stock returns. However, Campbell, Hilscher, and Szilagyi (2008) find that firms with high failure probability have lower rather than higher subsequent returns (anomaly 1). Campbell et al. suggest that their finding is a challenge to standard models of rational asset pricing. The failure probability is estimated by a dynamic logit model with both accounting and equity market variables as explanatory variables. Using Ohlson's (1980) O-score as the distress measure yields similar results (anomaly 2). Ohlson's (1980) O-score is calculated as the probability of bankruptcy in a static model using accounting variables, such as net income divided by assets, working capital divided by market assets, current liability divided by current assets, and etc. The failure probability is different from the O-score in that it is estimated by a dynamic model and uses several equity market variables, such as stock price, book-to-market, stock volatility, size relative to the S\&P 500, and cumulative excess return relative to the S\&P 500.

Net Stock Issues and Composite Equity Issues (3 83 4): The stock issuing market has long been viewed as producing an anomaly arising from sentiment-driven mispricing: smart managers issue shares when sentiment-driven traders push prices to overvalued levels. 
Ritter (1991) and Loughran and Ritter (1995) show that, in post-issue years, equity issuers underperform matching nonissuers with similar characteristics. Motivated by this evidence, Fama and French (2008) show that net stock issues and subsequent returns are negatively correlated. Following Fama and French (2008), we use Compustat data to measure net stock issues as the growth rate of the split-adjusted shares outstanding in the previous fiscal year (anomaly 3). Daniel and Titman (2006) also find that issuers underperform nonissuers using a measure they denote as composite equity issuance, defined as the growth in the firm's total market value of equity minus (i.e., not attributable to) the stock's rate of return (anomaly 4). We compute composite equity issuance in the same manner as Daniel and Titman.

Total Accruals (5): Sloan (1996) shows that firms with high accruals earn abnormally lower average returns than firms with low accruals, and he suggests that investors overestimate the persistence of the accrual component of earnings when forming earnings expectations. Here, total accruals are calculated as changes in non-cash working capital minus depreciation expense, scaled by average total assets for the previous two fiscal years.

Net Operating Assets (6): Hirshleifer, Hou, Teoh, and Zhang (2004) find that net operating assets, defined as the difference on the balance sheet between all operating assets and all operating liabilities, scaled by total assets, is a strong negative predictor of long-run stock returns. Specifically, we follow equations (4), (5), and (6) in that study when defining net operating assets. The authors suggest that investors with limited attention tend to focus on accounting profitability, neglecting information about cash profitability, in which case net operating assets, equivalently measured as the cumulative difference between operating income and free cash flow, captures such a bias.

Momentum (7): The momentum effect, discovered by Jegadeesh and Titman (1993), is one of the most robust anomalies in asset pricing. It refers to the phenomenon that high (low) past recent recent returns forecast high (low) future returns. The momentum portfolios we use are ranked based on cumulative returns from month -7 to month -2 , and the holding period for these portfolios is 6 -month. That is, it is a $6 / 1 / 6$ momentum strategy.

Gross Profitability Premium (8): Novy-Marx (2013) discovers that sorting on grossprofit-to-assets creates abnormal benchmark-adjusted returns, with more profitable firms having higher returns than less profitable ones. He argues that gross profits scaled by assets is the cleanest accounting measure of true economic profitability. The farther down the income statement one goes, the more polluted profitability measures become, and the less related they are to true economic profitability. 
Asset Growth (9): Cooper, Gulen, and Schill (2008) find companies that grow their total asset more earn lower subsequent returns. They suggest that this phenomenon is due to investors' initial overreaction to changes in future business prospects implied by asset expansions. Asset growth is measured as the growth rate of total assets in the previous fiscal year.

Return on Assets (10): Fama and French (2006) find that more profitable firms have higher expected returns than less profitable firms. Chen, Novy-Marx, and Zhang (2010) show that firms with higher past return-on-assets earn abnormally higher subsequent returns. Return-on-assets is measured as the ratio of quarterly earnings to last quarter's assets. Wang and $\mathrm{Yu}(2010)$ find that the anomaly exists primarily among firms with high arbitrage costs and high information uncertainty, suggesting that mispricing is a culprit.

Investment-to-Assets (11): Titman, Wei, and Xie (2004) and Xing (2008) show that higher past investment predicts abnormally lower future returns. Titman, Wei, and Xie (2004) attribute this anomaly to investors' initial underreactions to the overinvestment caused by managers' empire-building behavior. Here, investment-to-assets is measured as the annual change in gross property, plant, and equipment, plus the annual change in inventories, scaled by the lagged book value of assets. 
Table I

Individual-Stock IVOL and Number of Stocks in the Double-Sorted Portfolios

Panel A reports the typical individual-stock IVOL within each portfolio, first computing the median IVOL each month and then averaging the medians across months. Panel B reports the average number of stocks in each portfolio. The 25 portfolios are formed by independently sorting on IVOL and the mispricing measure. The latter is the average of the ranking percentiles produced by 11 anomaly variables. We compute IVOL, following Ang, Hodrick, Xing, and Zhang(2006), as the standard deviation of the most recent month's daily benchmark-adjusted returns, with the latter equal to the residuals in a regression of each stock's daily return on the three factors defined by Fama and French (1993): MKT, SMB, and HML. The sample period is from $8 / 1965$ to $1 / 2011$.

\begin{tabular}{lcccccc}
\hline & $\begin{array}{c}\text { Highest } \\
\text { IVOL }\end{array}$ & $\begin{array}{c}\text { Next } \\
20 \%\end{array}$ & $\begin{array}{c}\text { Next } \\
20 \%\end{array}$ & $\begin{array}{c}\text { Next } \\
20 \%\end{array}$ & $\begin{array}{c}\text { Lowest } \\
\text { IVOL }\end{array}$ & $\begin{array}{c}\text { All } \\
\text { Stocks }\end{array}$ \\
\hline \multicolumn{7}{c}{ Panel A: IVOL } \\
Most overpriced & 3.36 & 1.47 & 0.82 & 0.46 & 0.20 & 1.29 \\
Next 20\% & 3.22 & 1.45 & 0.81 & 0.45 & 0.19 & 0.88 \\
Next 20\% & 3.15 & 1.44 & 0.81 & 0.45 & 0.19 & 0.75 \\
Next 20\% & 3.11 & 1.43 & 0.80 & 0.44 & 0.19 & 0.68 \\
Most underpriced & 3.06 & 1.42 & 0.80 & 0.44 & 0.19 & 0.63 \\
All stocks & 3.21 & 1.44 & 0.81 & 0.45 & 0.19 & 0.81 \\
& Panel B: Number of Stocks & & \\
Most overpriced & 196 & 148 & 115 & 90 & 73 & 622 \\
Next 20\% & 131 & 132 & 128 & 120 & 111 & 623 \\
Next 20\% & 110 & 121 & 127 & 131 & 133 & 623 \\
Next 20\% & 98 & 114 & 127 & 138 & 145 & 623 \\
Most underpriced & 88 & 107 & 125 & 144 & 159 & 623 \\
All stocks & 622 & 623 & 623 & 623 & 622 & 3113 \\
\hline
\end{tabular}




\section{Table II \\ Idiosyncratic Volatility Effects in Underpriced versus Overpriced Stocks}

The table reports average benchmark-adjusted returns for portfolios formed by sorting stocks independently on idiosyncratic volatility (IVOL) and the mispricing measure. The mispricing measure is the average of the ranking percentiles produced by 11 anomaly variables. Also reported are results based on sorting by IVOL within the entire stock universe. Benchmark-adjusted returns are calculated as $a$ in the regression,

$$
R_{i, t}=a+b M K T_{t}+c S M B_{t}+d H M L_{t}+\epsilon_{i, t},
$$

where $R_{i, t}$ is the excess percent return in month $t$. The sample period is from $8 / 1965$ to $1 / 2011$. All t-statistics (in parentheses) are based on the heteroskedasticity-consistent standard errors of White (1980).

\begin{tabular}{lccccccc}
\hline & Highest & Next & Next & Next & Lowest & Highest & All \\
& IVOL & $20 \%$ & $20 \%$ & $20 \%$ & IVOL & -Lowest & Stocks \\
\hline Most overpriced & -1.89 & -0.95 & -0.72 & -0.47 & -0.39 & -1.50 & -0.81 \\
top 20\%) & $(-12.05)$ & $(-7.39)$ & $(-4.90)$ & $(-3.62)$ & $(-3.04)$ & $(-7.36)$ & $(-8.14)$ \\
Next 20\% & -0.88 & -0.41 & -0.31 & -0.21 & -0.04 & -0.84 & -0.23 \\
& $(-5.86)$ & $(-3.36)$ & $(-3.00)$ & $(-2.08)$ & $(-0.44)$ & $(-4.41)$ & $(-3.88)$ \\
Next 20\% & -0.09 & -0.01 & -0.05 & -0.12 & 0.02 & -0.10 & -0.07 \\
& $(-0.53)$ & $(-0.09)$ & $(-0.48)$ & $(-1.29)$ & $(0.18)$ & $(-0.53)$ & $(-1.47)$ \\
Next 20\% & -0.15 & 0.07 & 0.17 & 0.18 & 0.23 & -0.38 & 0.18 \\
& $(-0.80)$ & $(0.63)$ & $(1.87)$ & $(2.33)$ & $(3.22)$ & $(-1.78)$ & $(4.45)$ \\
Most underpriced & 0.56 & 0.68 & 0.51 & 0.33 & 0.14 & 0.41 & 0.28 \\
(bottom 20\%) & $(3.27)$ & $(4.91)$ & $(5.02)$ & $(4.10)$ & $(2.04)$ & $(2.16)$ & $(5.67)$ \\
& & & & & & & \\
Most overpriced - & -2.44 & -1.63 & -1.23 & -0.81 & -0.53 & -1.91 & -1.09 \\
most underpriced & $(-11.07)$ & $(-8.65)$ & $(-6.43)$ & $(-5.02)$ & $(-3.43)$ & $(-7.62)$ & $(-8.05)$ \\
& & & & & & & \\
All stocks & -0.69 & -0.12 & -0.00 & 0.05 & 0.08 & -0.78 & \\
& $(-6.09)$ & $(-1.56)$ & $(-0.01)$ & $(1.07)$ & $(1.86)$ & $(-5.50)$ & \\
\hline
\end{tabular}




\section{Table III \\ Idiosyncratic Volatility Effects in Subsamples of High versus Low Institutional Ownership}

The table reports average benchmark-adjusted returns for portfolios constructed by sorting independently on IVOL and institutional ownership (IO) within each quintile of the mispricing measure. The high-IO (low-IO) subsample consists of the top (bottom) 30\% of stocks sorted on size-adjusted IO, computed following Nagel (2005): Each quarter, we regress the logit of IO percentage on $\log ($ size $)$ and the square of $\log ($ size) and take the regression residual as size-adjusted IO. The data on institutional holdings are obtained from the Thomson Financial Institutional Holdings database. The mispricing quintiles are determined by sorting on the average ranking percentiles produced by 11 anomaly variables. Also reported are results based on sorting by IVOL and IO within the entire stock universe. The benchmark-adjusted returns are estimates of $a$ in the regression,

$$
R_{i, t}=a+b M K T_{t}+c S M B_{t}+d H M L_{t}+\epsilon_{i, t},
$$

where $R_{i, t}$ is the excess percent return in month $t$. The sample period is from $4 / 1980$ to $1 / 2011$. All t-statistics (in parentheses) are based on the heteroskedasticity-consistent standard errors of White (1980).

\begin{tabular}{|c|c|c|c|c|c|c|c|c|c|}
\hline & \multicolumn{3}{|c|}{ High-IO Sample } & \multicolumn{3}{|c|}{ Low-IO Sample } & \multicolumn{3}{|c|}{$\begin{array}{c}\text { High-IO Sample - } \\
\text { Low-IO Sample }\end{array}$} \\
\hline & $\begin{array}{l}\text { Highest } \\
\text { IVOL }\end{array}$ & $\begin{array}{l}\text { Lowest } \\
\text { IVOL }\end{array}$ & $\begin{array}{l}\text { Highest } \\
\text {-Lowest }\end{array}$ & $\begin{array}{l}\text { Highest } \\
\text { IVOL }\end{array}$ & $\begin{array}{l}\text { Lowest } \\
\text { IVOL }\end{array}$ & $\begin{array}{l}\text { Highest } \\
\text {-Lowest }\end{array}$ & $\begin{array}{l}\text { Highest } \\
\text { IVOL }\end{array}$ & $\begin{array}{l}\text { Lowest } \\
\text { IVOL }\end{array}$ & $\begin{array}{l}\text { Highest } \\
\text {-Lowest }\end{array}$ \\
\hline $\begin{array}{l}\text { Most overpriced } \\
\text { (top 20\%) }\end{array}$ & $\begin{array}{l}-2.65 \\
(-8.41)\end{array}$ & $\begin{array}{l}-0.61 \\
(-3.01)\end{array}$ & $\begin{array}{l}-2.03 \\
(-5.42)\end{array}$ & $\begin{array}{l}-3.11 \\
(-9.31)\end{array}$ & $\begin{array}{l}-0.16 \\
(-0.80)\end{array}$ & $\begin{array}{l}-2.95 \\
(-7.48)\end{array}$ & $\begin{array}{l}0.47 \\
(1.14)\end{array}$ & $\begin{array}{l}-0.45 \\
(-1.87)\end{array}$ & $\begin{array}{l}0.92 \\
(1.94)\end{array}$ \\
\hline Next $20 \%$ & $\begin{array}{l}-0.95 \\
(-3.44)\end{array}$ & $\begin{array}{l}-0.09 \\
(-0.48)\end{array}$ & $\begin{array}{l}-0.86 \\
(-2.70)\end{array}$ & $\begin{array}{l}-1.25 \\
(-4.56)\end{array}$ & $\begin{array}{c}0.14 \\
(0.84)\end{array}$ & $\begin{array}{l}-1.39 \\
(-4.34)\end{array}$ & $\begin{array}{c}0.30 \\
(0.82)\end{array}$ & $\begin{array}{l}-0.23 \\
(-1.08)\end{array}$ & $\begin{array}{c}0.52 \\
(1.29)\end{array}$ \\
\hline Next $20 \%$ & $\begin{array}{l}-0.61 \\
(-2.24)\end{array}$ & $\begin{array}{c}0.14 \\
(0.87)\end{array}$ & $\begin{array}{l}-0.75 \\
(-2.29)\end{array}$ & $\begin{array}{l}-0.23 \\
(-0.77)\end{array}$ & $\begin{array}{c}0.31 \\
(2.16)\end{array}$ & $\begin{array}{l}-0.54 \\
(-1.52)\end{array}$ & $\begin{array}{l}-0.38 \\
(-0.93)\end{array}$ & $\begin{array}{l}-0.17 \\
(-0.82)\end{array}$ & $\begin{array}{l}-0.21 \\
(-0.44)\end{array}$ \\
\hline Next $20 \%$ & $\begin{array}{l}-0.01 \\
(-0.04)\end{array}$ & $\begin{array}{c}0.30 \\
(1.94)\end{array}$ & $\begin{array}{l}-0.31 \\
(-0.95)\end{array}$ & $\begin{array}{l}-0.16 \\
(-0.59)\end{array}$ & $\begin{array}{c}0.10 \\
(0.74)\end{array}$ & $\begin{array}{l}-0.26 \\
(-0.83)\end{array}$ & $\begin{array}{c}0.15 \\
(0.43)\end{array}$ & $\begin{array}{c}0.20 \\
(0.99)\end{array}$ & $\begin{array}{l}-0.05 \\
(-0.11)\end{array}$ \\
\hline $\begin{array}{l}\text { Most underpriced } \\
\text { (bottom 20\%) }\end{array}$ & $\begin{array}{l}0.59 \\
(2.18)\end{array}$ & $\begin{array}{c}0.19 \\
(1.36)\end{array}$ & $\begin{array}{c}0.40 \\
(1.29)\end{array}$ & $\begin{array}{c}0.79 \\
(3.34)\end{array}$ & $\begin{array}{c}0.17 \\
(1.28)\end{array}$ & $\begin{array}{c}0.62 \\
(2.14)\end{array}$ & $\begin{array}{l}-0.20 \\
(-0.61)\end{array}$ & $\begin{array}{c}0.01 \\
(0.08)\end{array}$ & $\begin{array}{l}-0.22 \\
(-0.57)\end{array}$ \\
\hline $\begin{array}{l}\text { Most overpriced - } \\
\text { most underpriced }\end{array}$ & $\begin{array}{l}-3.23 \\
(-8.08)\end{array}$ & $\begin{array}{l}-0.80 \\
(-3.07)\end{array}$ & $\begin{array}{l}-2.43 \\
(-5.00)\end{array}$ & $\begin{array}{c}-3.90 \\
(-10.15)\end{array}$ & $\begin{array}{l}-0.33 \\
(-1.26)\end{array}$ & $\begin{array}{c}-3.57 \\
(-7.89)\end{array}$ & $\begin{array}{c}0.67 \\
(1.36)\end{array}$ & $\begin{array}{l}-0.47 \\
(-1.51)\end{array}$ & $\begin{array}{l}1.14 \\
(1.89)\end{array}$ \\
\hline All stocks & $\begin{array}{l}-0.65 \\
(-3.66)\end{array}$ & $\begin{array}{c}0.20 \\
(2.46)\end{array}$ & $\begin{array}{l}-0.86 \\
(-4.01)\end{array}$ & $\begin{array}{l}-1.06 \\
(-5.06)\end{array}$ & $\begin{array}{c}0.17 \\
(1.94)\end{array}$ & $\begin{array}{l}-1.23 \\
(-5.13)\end{array}$ & $\begin{array}{c}0.41 \\
(1.72)\end{array}$ & $\begin{array}{c}0.03 \\
(0.29)\end{array}$ & $\begin{array}{l}0.38 \\
(1.49)\end{array}$ \\
\hline
\end{tabular}


Table IV

Idiosyncratic Volatility Effects in High-Sentiment versus Low-Sentiment Periods

The table reports average benchmark-adjusted returns for portfolios containing stocks with either the highest (top 20\%) or lowest (bottom 20\%) idiosyncratic volatility (IVOL). The sort on IVOL is performed for stocks within a given range of over/under-pricing, as determined by an average of the ranking percentiles produced by 11 anomaly variables. Also reported are results based on sorting by IVOL within the entire stock universe. The benchmark-adjusted returns in high- and low-sentiment periods are estimates of $a_{H}$ and $a_{L}$ in the regression,

$$
R_{i, t}=a_{H} d_{H, t}+a_{L} d_{L, t}+b M K T_{t}+c S M B_{t}+d H M L_{t}+\epsilon_{i, t}
$$

where $d_{H, t}$ and $d_{L, t}$ are dummy variables indicating high- and low-sentiment periods, and $R_{i, t}$ is the excess percent return in month $t$. The sample period is from 8/1965 to $1 / 2011$. All t-statistics (in parentheses) are based on the heteroskedasticity-consistent standard errors of White (1980).

\begin{tabular}{|c|c|c|c|c|c|c|c|c|c|}
\hline & \multicolumn{3}{|c|}{ High-Sentiment Periods } & \multicolumn{3}{|c|}{ Low-Sentiment Periods } & \multicolumn{3}{|c|}{$\begin{array}{l}\text { High-Sentiment Periods - } \\
\text { Low-Sentiment Periods }\end{array}$} \\
\hline & $\begin{array}{l}\text { Highest } \\
\text { IVOL }\end{array}$ & $\begin{array}{l}\text { Lowest } \\
\text { IVOL }\end{array}$ & $\begin{array}{l}\text { Highest } \\
\text {-Lowest }\end{array}$ & $\begin{array}{l}\text { Highest } \\
\text { IVOL }\end{array}$ & $\begin{array}{l}\text { Lowest } \\
\text { IVOL }\end{array}$ & $\begin{array}{l}\text { Highest } \\
\text {-Lowest }\end{array}$ & $\begin{array}{l}\text { Highest } \\
\text { IVOL }\end{array}$ & $\begin{array}{l}\text { Lowest } \\
\text { IVOL }\end{array}$ & $\begin{array}{l}\text { Highest } \\
\text {-Lowest }\end{array}$ \\
\hline $\begin{array}{l}\text { Most overpriced } \\
\text { (top 20\%) }\end{array}$ & $\begin{array}{l}-2.84 \\
(-9.57)\end{array}$ & $\begin{array}{l}-0.54 \\
(-3.13)\end{array}$ & $\begin{array}{l}-2.30 \\
(-6.79)\end{array}$ & $\begin{array}{l}-1.66 \\
(-6.91)\end{array}$ & $\begin{array}{l}-0.36 \\
(-2.55)\end{array}$ & $\begin{array}{l}-1.30 \\
(-4.75)\end{array}$ & $\begin{array}{l}-1.18 \\
(-3.06)\end{array}$ & $\begin{array}{l}-0.18 \\
(-0.86)\end{array}$ & $\begin{array}{l}-1.00 \\
(-2.29)\end{array}$ \\
\hline Next $20 \%$ & $\begin{array}{l}-1.24 \\
(-5.28)\end{array}$ & $\begin{array}{l}-0.01 \\
(-0.04)\end{array}$ & $\begin{array}{l}-1.23 \\
(-4.31)\end{array}$ & $\begin{array}{l}-0.60 \\
(-2.77)\end{array}$ & $\begin{array}{l}-0.16 \\
(-1.26)\end{array}$ & $\begin{array}{l}-0.44 \\
(-1.71)\end{array}$ & $\begin{array}{l}-0.64 \\
(-2.02)\end{array}$ & $\begin{array}{c}0.15 \\
(0.82)\end{array}$ & $\begin{array}{l}-0.79 \\
(-2.07)\end{array}$ \\
\hline Next $20 \%$ & $\begin{array}{l}-0.17 \\
(-0.72)\end{array}$ & $\begin{array}{c}0.31 \\
(2.34)\end{array}$ & $\begin{array}{l}-0.48 \\
(-1.75)\end{array}$ & $\begin{array}{l}-0.10 \\
(-0.54)\end{array}$ & $\begin{array}{l}-0.22 \\
(-1.92)\end{array}$ & $\begin{array}{c}0.13 \\
(0.52)\end{array}$ & $\begin{array}{l}-0.07 \\
(-0.25)\end{array}$ & $\begin{array}{c}0.53 \\
(3.09)\end{array}$ & $\begin{array}{l}-0.60 \\
(-1.68)\end{array}$ \\
\hline Next $20 \%$ & $\begin{array}{l}-0.10 \\
(-0.35)\end{array}$ & $\begin{array}{c}0.19 \\
(1.44)\end{array}$ & $\begin{array}{l}-0.29 \\
(-0.84)\end{array}$ & $\begin{array}{c}-0.04 \\
(-0.23)\end{array}$ & $\begin{array}{c}0.11 \\
(1.29)\end{array}$ & $\begin{array}{l}-0.16 \\
(-0.75)\end{array}$ & $\begin{array}{l}-0.06 \\
(-0.18)\end{array}$ & $\begin{array}{c}0.08 \\
(0.49)\end{array}$ & $\begin{array}{l}-0.14 \\
(-0.34)\end{array}$ \\
\hline $\begin{array}{l}\text { Most underpriced } \\
\text { (bottom 20\%) }\end{array}$ & $\begin{array}{c}0.54 \\
(2.43)\end{array}$ & $\begin{array}{c}0.33 \\
(2.77)\end{array}$ & $\begin{array}{c}0.21 \\
(0.77)\end{array}$ & $\begin{array}{c}0.82 \\
(4.05)\end{array}$ & $\begin{array}{l}-0.12 \\
(-1.21)\end{array}$ & $\begin{array}{c}0.94 \\
(4.16)\end{array}$ & $\begin{array}{l}-0.28 \\
(-0.93)\end{array}$ & $\begin{array}{c}0.45 \\
(2.85)\end{array}$ & $\begin{array}{c}-0.73 \\
(-2.03)\end{array}$ \\
\hline $\begin{array}{l}\text { Most overpriced - } \\
\text { most underpriced }\end{array}$ & $\begin{array}{l}-3.38 \\
(-9.36)\end{array}$ & $\begin{array}{l}-0.87 \\
(-4.02)\end{array}$ & $\begin{array}{l}-2.51 \\
(-6.48)\end{array}$ & $\begin{array}{l}-2.48 \\
(-7.82)\end{array}$ & $\begin{array}{l}-0.24 \\
(-1.22)\end{array}$ & $\begin{array}{l}-2.24 \\
(-6.60)\end{array}$ & $\begin{array}{l}-0.90 \\
(-1.85)\end{array}$ & $\begin{array}{l}-0.63 \\
(-2.23)\end{array}$ & $\begin{array}{l}-0.27 \\
(-0.53)\end{array}$ \\
\hline All stocks & $\begin{array}{l}-1.06 \\
(-5.75)\end{array}$ & $\begin{array}{c}0.26 \\
(3.81)\end{array}$ & $\begin{array}{l}-1.32 \\
(-5.88)\end{array}$ & $\begin{array}{l}-0.33 \\
(-2.45)\end{array}$ & $\begin{array}{l}-0.10 \\
(-1.87)\end{array}$ & $\begin{array}{l}-0.23 \\
(-1.35)\end{array}$ & $\begin{array}{c}-0.72 \\
(-3.16)\end{array}$ & $\begin{array}{c}0.36 \\
(4.16)\end{array}$ & $\begin{array}{l}-1.09 \\
(-3.82)\end{array}$ \\
\hline
\end{tabular}




\section{Table V}

Idiosyncratic-Volatility Effects and Investor Sentiment: Predictive Regressions

The table reports estimates of $b$ in the regression,

$$
R_{i, t}=a+b S_{t-1}+c M K T_{t}+d S M B_{t}+e H M L_{t}+u_{t},
$$

where $R_{i, t}$ is the excess percent return in month $t$, and $S_{t}$ is the level of the investor-sentiment index of Baker and Wurgler (2006). The sort on IVOL is performed for stocks within a given range of over/under-pricing, as determined by an average of the ranking percentiles produced by 11 anomaly variables. Also reported are results based on sorting by IVOL within the entire stock universe. The sample period is from 8/1965 to $1 / 2011$. All t-statistics are based on the heteroskedasticity-consistent standard errors of White (1980).

\begin{tabular}{|c|c|c|c|c|c|c|}
\hline & \multicolumn{2}{|c|}{ Highest IVOL } & \multicolumn{2}{|c|}{ Lowest IVOL } & \multicolumn{2}{|c|}{ Highest - Lowest } \\
\hline & $\hat{b}$ & t-stat. & $\hat{b}$ & t-stat. & $\hat{b}$ & t-stat. \\
\hline Most overpriced (top 20\%) & -0.78 & -3.74 & 0.01 & 0.08 & -0.79 & -3.49 \\
\hline Next $20 \%$ & -0.40 & -2.50 & 0.09 & 0.97 & -0.48 & -2.50 \\
\hline Next $20 \%$ & -0.10 & -0.74 & 0.30 & 3.20 & -0.40 & -2.18 \\
\hline Next $20 \%$ & -0.13 & -0.81 & 0.05 & 0.60 & -0.18 & -0.93 \\
\hline Most underpriced (bottom 20\%) & -0.12 & -0.92 & 0.16 & 1.81 & -0.28 & -1.80 \\
\hline Most overpriced - most underpriced & -0.66 & -2.76 & -0.15 & -1.12 & -0.50 & -2.20 \\
\hline All stocks & -0.48 & -3.92 & 0.18 & 3.77 & -0.66 & -4.25 \\
\hline
\end{tabular}


Table VI

\section{Idiosyncratic-Volatility Effects and Investor Sentiment: Predictive Regressions with Macroeconomic Controls}

The table reports estimates of $b$ in the regressions,

$$
\begin{aligned}
& R_{i, t}=a+b \tilde{S}_{t-1}+c M K T_{t}+d S M B_{t}+e H M L_{t}+u_{t} \text { (Panel A) } \\
& R_{i, t}=a+b \tilde{S}_{t-1}+c M K T_{t}+d S M B_{t}+e H M L_{t}+\sum_{j=1}^{6} m_{j} X_{j, t-1}+u_{t} \quad \text { (Panel B), }
\end{aligned}
$$

where $R_{i, t}$ is the excess percent return in month $t, \tilde{S}_{t}$ is the level of the investor-sentiment index of Baker and Wurgler (2006) that is orthogonalized with respect to six macro variables, and $X_{1, t}$, $\cdots, X_{6, t}$ are the term premium, the default premium, the interest rate, the inflation rate, the surplus ratio, and the consumption-wealth ratio. The sort on IVOL is performed for stocks within a given range of over/under-pricing, as determined by an average of the ranking percentiles produced by 11 anomaly variables. Also reported are results based on sorting by IVOL within the entire stock universe. The sample period is from 8/1965 to 1/2011. All t-statistics are based on the

\begin{tabular}{|c|c|c|c|c|c|c|}
\hline & \multicolumn{2}{|c|}{ Highest IVOL } & \multicolumn{2}{|c|}{ Lowest IVOL } & \multicolumn{2}{|c|}{ Highest - Lowest } \\
\hline & $\hat{b}$ & t-stat. & $\hat{b}$ & t-stat. & $\hat{b}$ & t-stat. \\
\hline \multicolumn{7}{|c|}{ Panel A. $R_{i, t}=a+b \tilde{S}_{t-1}+c M K T_{t}+d S M B_{t}+e H M L_{t}+u_{t}$} \\
\hline Most overpriced (top 20\%) & -0.74 & -3.56 & 0.03 & 0.28 & -0.76 & -3.42 \\
\hline Next $20 \%$ & -0.45 & -2.89 & 0.08 & 0.92 & -0.53 & -2.81 \\
\hline Next $20 \%$ & -0.17 & -1.24 & 0.29 & 3.10 & -0.46 & -2.49 \\
\hline Next $20 \%$ & -0.17 & -1.12 & 0.04 & 0.52 & -0.22 & -1.14 \\
\hline Most underpriced (bottom 20\%) & -0.20 & -1.54 & 0.15 & 1.63 & -0.35 & -2.22 \\
\hline Most overpriced - most underpriced & -0.54 & -2.28 & -0.12 & -0.87 & -0.42 & -1.88 \\
\hline All stocks & -0.52 & -4.31 & 0.17 & 3.53 & -0.69 & -4.50 \\
\hline \multicolumn{7}{|c|}{ Panel B. $R_{i, t}=a+b \tilde{S}_{t-1}+c M K T_{t}+d S M B_{t}+e H M L_{t}+\sum_{j=1}^{6} m_{j} X_{j, t-1}+u_{t}$} \\
\hline Most overpriced (top 20\%) & -0.64 & -2.68 & -0.08 & -0.67 & -0.56 & -2.15 \\
\hline Next $20 \%$ & -0.46 & -2.52 & 0.04 & 0.41 & -0.50 & -2.29 \\
\hline Next $20 \%$ & -0.10 & -0.65 & 0.25 & 2.56 & -0.35 & -1.73 \\
\hline Next $20 \%$ & -0.09 & -0.49 & 0.09 & 0.97 & -0.17 & -0.83 \\
\hline Most underpriced (bottom 20\%) & -0.18 & -1.21 & 0.07 & 0.70 & -0.24 & -1.42 \\
\hline Most overpriced - most underpriced & -0.46 & -1.75 & -0.14 & -0.94 & -0.32 & -1.25 \\
\hline All stocks & -0.50 & -3.58 & 0.15 & 2.84 & -0.65 & -3.69 \\
\hline
\end{tabular}
heteroskedasticity-consistent standard errors of White (1980). 


\section{Table VII}

\section{Idiosyncratic Volatility Effects in Underpriced versus Overpriced Stocks Under Various Thresholds for Market Capitalization}

The table reports average benchmark-adjusted returns for portfolios formed by sorting stocks independently on idiosyncratic volatility (IVOL) and the mispricing measure. In each panel, the universe of stocks being sorted consists of all those with market capitalization exceeding a given percentile. The mispricing measure is determined by an average of the ranking percentiles produced by 11 anomaly variables. Also reported are results based on sorting by IVOL within the entire universe. Benchmark-adjusted returns are calculated as $a$ in the regression,

$$
R_{i, t}=a+b M K T_{t}+c S M B_{t}+d H M L_{t}+\epsilon_{i, t},
$$

where $R_{i, t}$ is the excess percent return in month $t$. The sample period is from $8 / 1965$ to $1 / 2011$. All t-statistics (in parentheses) are based on the heteroskedasticity-consistent standard errors of White (1980). In Panels A, $\mathrm{B}, \mathrm{C}$, and $\mathrm{D}$, the smallest $20 \%, 40 \%, 60 \%$, and $80 \%$ of the firms are deleted from the portfolio formation, respectively.

\begin{tabular}{|c|c|c|c|c|c|c|c|}
\hline & $\begin{array}{l}\text { Highest } \\
\text { IVOL } \\
\end{array}$ & $\begin{array}{l}\text { Next } \\
20 \% \\
\end{array}$ & $\begin{array}{l}\text { Next } \\
20 \% \\
\end{array}$ & $\begin{array}{l}\text { Next } \\
20 \% \\
\end{array}$ & $\begin{array}{l}\text { Lowest } \\
\text { IVOL } \\
\end{array}$ & $\begin{array}{c}\text { Highest } \\
\text {-Lowest }\end{array}$ & $\begin{array}{c}\text { All } \\
\text { Stocks }\end{array}$ \\
\hline \multicolumn{8}{|c|}{ Panel A: $20 \%$ Smallest Stocks Deleted } \\
\hline $\begin{array}{l}\text { Most overpriced } \\
\text { (top 20\%) }\end{array}$ & $\begin{array}{c}-1.66 \\
(-10.74)\end{array}$ & $\begin{array}{l}-0.85 \\
(-6.01)\end{array}$ & $\begin{array}{l}-0.56 \\
(-4.06)\end{array}$ & $\begin{array}{l}-0.54 \\
(-4.05)\end{array}$ & $\begin{array}{l}-0.35 \\
(-2.76)\end{array}$ & $\begin{array}{l}-1.31 \\
(-6.56)\end{array}$ & $\begin{array}{r}-0.79 \\
(-7.88\end{array}$ \\
\hline Next $20 \%$ & $\begin{array}{l}-0.86 \\
(-5.75)\end{array}$ & $\begin{array}{l}-0.39 \\
(-3.28)\end{array}$ & $\begin{array}{l}-0.31 \\
(-3.09)\end{array}$ & $\begin{array}{l}-0.24 \\
(-2.40)\end{array}$ & $\begin{array}{l}-0.04 \\
(-0.45)\end{array}$ & $\begin{array}{l}-0.82 \\
(-4.42)\end{array}$ & $\begin{array}{l}-0.25 \\
(-4.30\end{array}$ \\
\hline Next $20 \%$ & $\begin{array}{l}-0.12 \\
(-0.77)\end{array}$ & $\begin{array}{c}0.09 \\
(0.80)\end{array}$ & $\begin{array}{c}0.01 \\
(0.13)\end{array}$ & $\begin{array}{l}-0.12 \\
(-1.27)\end{array}$ & $\begin{array}{c}0.03 \\
(0.40)\end{array}$ & $\begin{array}{l}-0.15 \\
(-0.80)\end{array}$ & $\begin{array}{r}-0.04 \\
(-0.92\end{array}$ \\
\hline Next $20 \%$ & $\begin{array}{l}-0.08 \\
(-0.43)\end{array}$ & $\begin{array}{l}0.16 \\
(1.45)\end{array}$ & $\begin{array}{c}0.19 \\
(2.11)\end{array}$ & $\begin{array}{c}0.11 \\
(1.47)\end{array}$ & $\begin{array}{c}0.21 \\
(2.91)\end{array}$ & $\begin{array}{l}-0.29 \\
(-1.42)\end{array}$ & $\begin{array}{c}0.16 \\
(3.72)\end{array}$ \\
\hline $\begin{array}{l}\text { Most underpriced } \\
\text { (bottom 20\%) }\end{array}$ & $\begin{array}{l}0.46 \\
(2.83)\end{array}$ & $\begin{array}{c}0.73 \\
(5.66)\end{array}$ & $\begin{array}{c}0.47 \\
(4.72)\end{array}$ & $\begin{array}{c}0.31 \\
(3.78)\end{array}$ & $\begin{array}{l}0.15 \\
(2.25)\end{array}$ & $\begin{array}{c}0.31 \\
(1.64)\end{array}$ & $\begin{array}{c}0.28 \\
(5.68)\end{array}$ \\
\hline $\begin{array}{l}\text { Most overpriced - } \\
\text { Most underpriced }\end{array}$ & $\begin{array}{l}-2.12 \\
(-9.84)\end{array}$ & $\begin{array}{l}-1.58 \\
(-8.22)\end{array}$ & $\begin{array}{l}-1.03 \\
(-5.69)\end{array}$ & $\begin{array}{l}-0.85 \\
(-5.19)\end{array}$ & $\begin{array}{l}-0.50 \\
(-3.27)\end{array}$ & $\begin{array}{l}-1.62 \\
(-6.54)\end{array}$ & $\begin{array}{l}-1.07 \\
(-7.81)\end{array}$ \\
\hline All stocks & $\begin{array}{l}-0.64 \\
(-5.61)\end{array}$ & $\begin{array}{l}-0.04 \\
(-0.58)\end{array}$ & $\begin{array}{c}0.04 \\
(0.76)\end{array}$ & $\begin{array}{c}0.01 \\
(0.29)\end{array}$ & $\begin{array}{c}0.09 \\
(2.12)\end{array}$ & $\begin{array}{l}-0.73 \\
(-5.20)\end{array}$ & \\
\hline \multicolumn{8}{|c|}{ Panel B: $40 \%$ Smallest Stocks Deleted } \\
\hline $\begin{array}{l}\text { Most overpriced } \\
\text { (top 20\%) }\end{array}$ & $\begin{array}{l}-1.44 \\
(-9.66)\end{array}$ & $\begin{array}{l}-0.88 \\
(-6.12)\end{array}$ & $\begin{array}{l}-0.56 \\
(-4.46)\end{array}$ & $\begin{array}{l}-0.40 \\
(-3.11)\end{array}$ & $\begin{array}{l}-0.39 \\
(-3.12)\end{array}$ & $\begin{array}{l}-1.05 \\
(-5.42)\end{array}$ & $\begin{array}{r}-0.74 \\
(-7.70)\end{array}$ \\
\hline Next $20 \%$ & $\begin{array}{l}-0.65 \\
(-4.15)\end{array}$ & $\begin{array}{l}-0.25 \\
(-2.16)\end{array}$ & $\begin{array}{l}-0.29 \\
(-2.89)\end{array}$ & $\begin{array}{l}-0.21 \\
(-2.03)\end{array}$ & $\begin{array}{l}-0.01 \\
(-0.15)\end{array}$ & $\begin{array}{l}-0.63 \\
(-3.23)\end{array}$ & $\begin{array}{r}-0.24 \\
(-4.16\end{array}$ \\
\hline Next $20 \%$ & $\begin{array}{l}0.05 \\
(0.34)\end{array}$ & $\begin{array}{c}0.06 \\
(0.57)\end{array}$ & $\begin{array}{c}0.12 \\
(1.19)\end{array}$ & $\begin{array}{l}-0.12 \\
(-1.25)\end{array}$ & $\begin{array}{c}0.03 \\
(0.34)\end{array}$ & $\begin{array}{c}0.02 \\
(0.11)\end{array}$ & $\begin{array}{l}-0.01 \\
(-0.15)\end{array}$ \\
\hline Next $20 \%$ & $\begin{array}{l}0.03 \\
(0.19)\end{array}$ & $\begin{array}{c}0.15 \\
(1.36)\end{array}$ & $\begin{array}{c}0.14 \\
(1.49)\end{array}$ & $\begin{array}{c}0.18 \\
(2.28)\end{array}$ & $\begin{array}{c}0.20 \\
(2.69)\end{array}$ & $\begin{array}{l}-0.17 \\
(-0.90)\end{array}$ & $\begin{array}{c}0.15 \\
(3.46)\end{array}$ \\
\hline $\begin{array}{l}\text { Most underpriced } \\
\text { (bottom 20\%) }\end{array}$ & $\begin{array}{l}0.55 \\
(3.21)\end{array}$ & $\begin{array}{c}0.65 \\
(5.30)\end{array}$ & $\begin{array}{c}0.42 \\
(4.18)\end{array}$ & $\begin{array}{c}0.27 \\
(3.25)\end{array}$ & $\begin{array}{l}0.16 \\
(2.17)\end{array}$ & $\begin{array}{c}0.39 \\
(2.00)\end{array}$ & $\begin{array}{c}0.28 \\
(5.61)\end{array}$ \\
\hline $\begin{array}{l}\text { Most overpriced - } \\
\text { Most underpriced }\end{array}$ & $\begin{array}{l}-1.99 \\
(-9.37)\end{array}$ & $\begin{array}{l}-1.52 \\
(-7.72)\end{array}$ & $\begin{array}{l}-0.98 \\
(-5.56)\end{array}$ & $\begin{array}{l}-0.67 \\
(-4.19)\end{array}$ & $\begin{array}{l}-0.55 \\
(-3.50)\end{array}$ & $\begin{array}{l}-1.44 \\
(-6.00)\end{array}$ & $\begin{array}{l}-1.02 \\
(-7.61)\end{array}$ \\
\hline All stocks & $\begin{array}{l}-0.46 \\
(-4.01)\end{array}$ & $\begin{array}{l}-0.05 \\
(-0.67)\end{array}$ & $\begin{array}{c}0.04 \\
(0.77)\end{array}$ & $\begin{array}{c}0.03 \\
(0.79)\end{array}$ & $\begin{array}{c}0.09 \\
(2.00)\end{array}$ & $\begin{array}{l}-0.55 \\
(-3.87)\end{array}$ & \\
\hline
\end{tabular}




\section{Table VII-continued \\ Idiosyncratic Volatility Effects in Underpriced versus Overpriced Stocks Under Various Thresholds for Market Capitalization}

The table reports average benchmark-adjusted returns for portfolios formed by sorting stocks independently on idiosyncratic volatility (IVOL) and the mispricing measure. In each panel, the universe of stocks being sorted consists of all those with market capitalization exceeding a given percentile. The mispricing measure is determined by an average of the ranking percentiles produced by 11 anomaly variables. Also reported are results based on sorting by IVOL within the entire universe. Benchmark-adjusted returns are calculated as $a$ in the regression,

$$
R_{i, t}=a+b M K T_{t}+c S M B_{t}+d H M L_{t}+\epsilon_{i, t},
$$

where $R_{i, t}$ is the excess percent return in month $t$. The sample period is from $8 / 1965$ to $1 / 2011$. All t-statistics (in parentheses) are based on the heteroskedasticity-consistent standard errors of White (1980). In Panels A, $\mathrm{B}, \mathrm{C}$, and $\mathrm{D}$, the smallest $20 \%, 40 \%, 60 \%$, and $80 \%$ of the firms are deleted from the portfolio formation, respectively.

\begin{tabular}{|c|c|c|c|c|c|c|c|}
\hline & $\begin{array}{l}\text { Highest } \\
\text { IVOL } \\
\end{array}$ & $\begin{array}{l}\text { Next } \\
20 \% \\
\end{array}$ & $\begin{array}{l}\text { Next } \\
20 \% \\
\end{array}$ & $\begin{array}{l}\text { Next } \\
20 \% \\
\end{array}$ & $\begin{array}{l}\text { Lowest } \\
\text { IVOL } \\
\end{array}$ & $\begin{array}{c}\text { Highest } \\
\text {-Lowest }\end{array}$ & $\begin{array}{c}\text { All } \\
\text { Stocks }\end{array}$ \\
\hline \multicolumn{8}{|c|}{ Panel C: $60 \%$ Smallest Stocks Deleted } \\
\hline $\begin{array}{l}\text { Most overpriced } \\
\text { (top 20\%) }\end{array}$ & $\begin{array}{l}-1.25 \\
(-8.19)\end{array}$ & $\begin{array}{l}-0.58 \\
(-3.97)\end{array}$ & $\begin{array}{l}-0.51 \\
(-4.10)\end{array}$ & $\begin{array}{l}-0.34 \\
(-2.74)\end{array}$ & $\begin{array}{l}-0.23 \\
(-1.93)\end{array}$ & $\begin{array}{l}-1.02 \\
(-5.07)\end{array}$ & $\begin{array}{l}-0.64 \\
(-6.75)\end{array}$ \\
\hline Next $20 \%$ & $\begin{array}{l}-0.46 \\
(-3.23)\end{array}$ & $\begin{array}{l}-0.25 \\
(-2.20)\end{array}$ & $\begin{array}{l}-0.26 \\
(-2.63)\end{array}$ & $\begin{array}{l}-0.20 \\
(-1.82)\end{array}$ & $\begin{array}{l}-0.02 \\
(-0.24)\end{array}$ & $\begin{array}{l}-0.44 \\
(-2.30)\end{array}$ & $\begin{array}{l}-0.21 \\
(-3.76)\end{array}$ \\
\hline Next $20 \%$ & $\begin{array}{c}0.01 \\
(0.09)\end{array}$ & $\begin{array}{c}0.19 \\
(1.90)\end{array}$ & $\begin{array}{c}-0.03 \\
(-0.30)\end{array}$ & $\begin{array}{c}-0.03 \\
(-0.27)\end{array}$ & $\begin{array}{c}0.17 \\
(1.73)\end{array}$ & $\begin{array}{l}-0.16 \\
(-0.81)\end{array}$ & $\begin{array}{c}0.04 \\
(0.83)\end{array}$ \\
\hline Next $20 \%$ & $\begin{array}{c}0.22 \\
(1.38)\end{array}$ & $\begin{array}{l}0.05 \\
(0.47)\end{array}$ & $\begin{array}{l}0.11 \\
(1.13)\end{array}$ & $\begin{array}{c}0.19 \\
(2.21)\end{array}$ & $\begin{array}{c}0.21 \\
(2.36)\end{array}$ & $\begin{array}{c}0.01 \\
(0.06)\end{array}$ & $\begin{array}{c}0.15 \\
(3.08)\end{array}$ \\
\hline $\begin{array}{l}\text { Most underpriced } \\
\text { (bottom 20\%) }\end{array}$ & $\begin{array}{c}0.54 \\
(3.15)\end{array}$ & $\begin{array}{c}0.61 \\
(5.29)\end{array}$ & $\begin{array}{c}0.40 \\
(4.14)\end{array}$ & $\begin{array}{c}0.23 \\
(2.63)\end{array}$ & $\begin{array}{c}0.13 \\
(1.74)\end{array}$ & $\begin{array}{c}0.40 \\
(2.08)\end{array}$ & $\begin{array}{c}0.27 \\
(5.17)\end{array}$ \\
\hline $\begin{array}{l}\text { Most overpriced - } \\
\text { Most underpriced }\end{array}$ & $\begin{array}{l}-1.79 \\
(-8.55)\end{array}$ & $\begin{array}{l}-1.19 \\
(-6.08)\end{array}$ & $\begin{array}{l}-0.91 \\
(-5.33)\end{array}$ & $\begin{array}{l}-0.57 \\
(-3.39)\end{array}$ & $\begin{array}{c}-0.37 \\
(-2.39)\end{array}$ & $\begin{array}{l}-1.42 \\
(-6.10)\end{array}$ & $\begin{array}{l}-0.91 \\
(-6.78)\end{array}$ \\
\hline All stocks & $\begin{array}{c}-0.34 \\
(-3.11)\end{array}$ & $\begin{array}{l}0.01 \\
(0.15)\end{array}$ & $\begin{array}{l}0.01 \\
(0.14)\end{array}$ & $\begin{array}{c}0.06 \\
(1.20)\end{array}$ & $\begin{array}{c}0.10 \\
(2.18)\end{array}$ & $\begin{array}{c}-0.45 \\
(-3.20)\end{array}$ & \\
\hline \multicolumn{8}{|c|}{ Panel D: $80 \%$ Smallest Stocks Deleted } \\
\hline $\begin{array}{l}\text { Most overpriced } \\
\text { (top 20\%) }\end{array}$ & $\begin{array}{c}-0.88 \\
(-5.55)\end{array}$ & $\begin{array}{l}-0.48 \\
(-3.34)\end{array}$ & $\begin{array}{l}-0.59 \\
(-4.51)\end{array}$ & $\begin{array}{l}-0.32 \\
(-2.21)\end{array}$ & $\begin{array}{l}-0.12 \\
(-0.98)\end{array}$ & $\begin{array}{c}-0.77 \\
(-3.66)\end{array}$ & $\begin{array}{l}-0.56 \\
(-5.89)\end{array}$ \\
\hline Next $20 \%$ & $\begin{array}{l}-0.30 \\
(-1.99)\end{array}$ & $\begin{array}{l}-0.17 \\
(-1.54)\end{array}$ & $\begin{array}{l}-0.12 \\
(-1.05)\end{array}$ & $\begin{array}{l}-0.14 \\
(-1.36)\end{array}$ & $\begin{array}{l}-0.03 \\
(-0.27)\end{array}$ & $\begin{array}{l}-0.27 \\
(-1.27)\end{array}$ & $\begin{array}{l}-0.17 \\
(-2.94)\end{array}$ \\
\hline Next $20 \%$ & $\begin{array}{c}0.02 \\
(0.11)\end{array}$ & $\begin{array}{c}0.06 \\
(0.53)\end{array}$ & $\begin{array}{c}0.06 \\
(0.62)\end{array}$ & $\begin{array}{c}0.12 \\
(1.21)\end{array}$ & $\begin{array}{c}0.17 \\
(1.76)\end{array}$ & $\begin{array}{c}-0.16 \\
(-0.80)\end{array}$ & $\begin{array}{c}0.06 \\
(1.30)\end{array}$ \\
\hline Next $20 \%$ & $\begin{array}{l}0.25 \\
(1.72)\end{array}$ & $\begin{array}{c}0.05 \\
(0.48)\end{array}$ & $\begin{array}{l}0.18 \\
(1.66)\end{array}$ & $\begin{array}{c}0.25 \\
(2.65)\end{array}$ & $\begin{array}{c}0.21 \\
(2.21)\end{array}$ & $\begin{array}{c}0.05 \\
(0.27)\end{array}$ & $\begin{array}{c}0.16 \\
(3.06)\end{array}$ \\
\hline $\begin{array}{l}\text { Most underpriced } \\
\text { (bottom 20\%) }\end{array}$ & $\begin{array}{c}0.51 \\
(2.90)\end{array}$ & $\begin{array}{c}0.43 \\
(3.56)\end{array}$ & $\begin{array}{c}0.44 \\
(4.09)\end{array}$ & $\begin{array}{c}0.28 \\
(3.15)\end{array}$ & $\begin{array}{c}0.03 \\
(0.40)\end{array}$ & $\begin{array}{c}0.47 \\
(2.34)\end{array}$ & $\begin{array}{c}0.26 \\
(4.34)\end{array}$ \\
\hline $\begin{array}{l}\text { Most overpriced - } \\
\text { Most underpriced }\end{array}$ & $\begin{array}{l}-1.39 \\
(-6.23)\end{array}$ & $\begin{array}{l}-0.91 \\
(-4.45)\end{array}$ & $\begin{array}{l}-1.03 \\
(-5.59)\end{array}$ & $\begin{array}{l}-0.60 \\
(-3.37)\end{array}$ & $\begin{array}{l}-0.16 \\
(-0.99)\end{array}$ & $\begin{array}{l}-1.23 \\
(-4.82)\end{array}$ & $\begin{array}{l}-0.82 \\
(-5.86)\end{array}$ \\
\hline All stocks & $\begin{array}{l}-0.19 \\
(-1.80)\end{array}$ & $\begin{array}{l}-0.02 \\
(-0.29)\end{array}$ & $\begin{array}{l}0.07 \\
(1.34)\end{array}$ & $\begin{array}{c}0.10 \\
(1.84)\end{array}$ & $\begin{array}{c}0.07 \\
(1.39)\end{array}$ & $\begin{array}{l}-0.26 \\
(-1.88)\end{array}$ & \\
\hline
\end{tabular}


Table VIII

\section{Idiosyncratic-Volatility Effects and Investor Sentiment: Predictive Regressions Under Various Thresholds for Market Capitalization}

The table reports estimates of $b$ in the regression,

$$
R_{i, t}=a+b S_{t-1}+c M K T_{t}+d S M B_{t}+e H M L_{t}+u_{t}
$$

where $R_{i, t}$ is the excess percent return in month $t$, and $S_{t}$ is the level of the investor-sentiment index of Baker and Wurgler (2006). The sort on IVOL is performed for stocks within a given range of over/under-pricing, as determined by an average of the ranking percentiles produced by 11 anomaly variables. In each panel, the universe of stocks being sorted consists of all those with market capitalization exceeding a given percentile. Also reported are results based on sorting by IVOL within the entire universe. The sample period is from 8/1965 to $1 / 2011$. All t-statistics are based on the heteroskedasticity-consistent standard errors of White (1980). In Panels A, B, C, and D, the smallest 20\%, 40\%, 60\%, and $80 \%$ of the firms are deleted from the portfolio formation, respectively.

\begin{tabular}{|c|c|c|c|c|c|c|}
\hline & \multicolumn{2}{|c|}{ Highest IVOL } & \multicolumn{2}{|c|}{ Lowest IVOL } & \multicolumn{2}{|c|}{ Highest - Lowest } \\
\hline & $\hat{b}$ & t-stat. & $\hat{b}$ & t-stat. & $\hat{b}$ & t-stat. \\
\hline \multicolumn{7}{|c|}{ Panel A: 20\% Smallest Stocks Deleted } \\
\hline $\begin{array}{l}\text { Most overpriced (top 20\%) } \\
\text { Next } 20 \% \\
\text { Next } 20 \% \\
\text { Next } 20 \% \\
\text { Most underpriced (bottom 20\%) }\end{array}$ & $\begin{array}{l}-0.79 \\
-0.44 \\
-0.11 \\
-0.10 \\
-0.07\end{array}$ & $\begin{array}{l}-3.82 \\
-2.83 \\
-0.84 \\
-0.65 \\
-0.52\end{array}$ & $\begin{array}{l}0.00 \\
0.10 \\
0.31 \\
0.08 \\
0.14\end{array}$ & $\begin{array}{l}0.04 \\
1.10 \\
3.38 \\
0.95 \\
1.50\end{array}$ & $\begin{array}{l}-0.79 \\
-0.53 \\
-0.42 \\
-0.18 \\
-0.20\end{array}$ & $\begin{array}{l}-3.54 \\
-2.80 \\
-2.41 \\
-0.97 \\
-1.29\end{array}$ \\
\hline Most overpriced - most underpriced & -0.72 & -3.07 & -0.13 & -0.95 & -0.59 & -2.62 \\
\hline All stocks & -0.46 & -3.80 & 0.18 & 3.76 & -0.64 & -4.15 \\
\hline \multicolumn{7}{|c|}{ Panel B: $40 \%$ Smallest Stocks Deleted } \\
\hline $\begin{array}{l}\text { Most overpriced (top 20\%) } \\
\text { Next } 20 \% \\
\text { Next } 20 \% \\
\text { Next } 20 \% \\
\text { Most underpriced (bottom 20\%) }\end{array}$ & $\begin{array}{c}-0.83 \\
-0.38 \\
-0.19 \\
0.01 \\
-0.03\end{array}$ & $\begin{array}{c}-4.03 \\
-2.31 \\
-1.48 \\
0.11 \\
-0.24\end{array}$ & $\begin{array}{c}-0.02 \\
0.15 \\
0.31 \\
0.12 \\
0.14\end{array}$ & $\begin{array}{l}-0.24 \\
1.60 \\
3.13 \\
1.53 \\
1.45\end{array}$ & $\begin{array}{l}-0.80 \\
-0.53 \\
-0.50 \\
-0.11 \\
-0.17\end{array}$ & $\begin{array}{l}-3.56 \\
-2.58 \\
-2.80 \\
-0.61 \\
-1.02\end{array}$ \\
\hline Most overpriced - most underpriced & -0.79 & -3.45 & -0.16 & -1.12 & -0.63 & -2.79 \\
\hline All stocks & -0.43 & -3.48 & 0.19 & 3.93 & -0.62 & -3.93 \\
\hline \multicolumn{7}{|c|}{ Panel C: $60 \%$ Smallest Stocks Deleted } \\
\hline $\begin{array}{l}\text { Most overpriced (top 20\%) } \\
\text { Next } 20 \% \\
\text { Next } 20 \% \\
\text { Next } 20 \% \\
\text { Most underpriced (bottom 20\%) }\end{array}$ & $\begin{array}{c}-0.78 \\
-0.33 \\
-0.01 \\
0.03 \\
0.03\end{array}$ & $\begin{array}{c}-3.86 \\
-2.14 \\
-0.09 \\
0.21 \\
0.20\end{array}$ & $\begin{array}{l}0.04 \\
0.11 \\
0.27 \\
0.14 \\
0.14\end{array}$ & $\begin{array}{l}0.39 \\
1.23 \\
2.64 \\
1.73 \\
1.44\end{array}$ & $\begin{array}{l}-0.81 \\
-0.44 \\
-0.29 \\
-0.11 \\
-0.11\end{array}$ & $\begin{array}{l}-3.77 \\
-2.25 \\
-1.51 \\
-0.70 \\
-0.64\end{array}$ \\
\hline Most overpriced - most underpriced & -0.80 & -3.46 & -0.10 & -0.70 & -0.70 & -3.23 \\
\hline All stocks & -0.35 & -2.82 & 0.17 & 3.49 & -0.52 & -3.27 \\
\hline \multicolumn{7}{|c|}{ Panel D: $80 \%$ Smallest Stocks Deleted } \\
\hline $\begin{array}{l}\text { Most overpriced (top 20\%) } \\
\text { Next } 20 \% \\
\text { Next } 20 \% \\
\text { Next } 20 \% \\
\text { Most underpriced (bottom 20\%) }\end{array}$ & $\begin{array}{c}-0.80 \\
-0.34 \\
0.00 \\
0.02 \\
0.04\end{array}$ & $\begin{array}{l}-3.87 \\
-2.29 \\
0.01 \\
0.16 \\
0.25\end{array}$ & $\begin{array}{l}0.11 \\
0.18 \\
0.29 \\
0.16 \\
0.11\end{array}$ & $\begin{array}{l}0.94 \\
1.75 \\
2.82 \\
1.76 \\
1.11\end{array}$ & $\begin{array}{l}-0.91 \\
-0.52 \\
-0.29 \\
-0.14 \\
-0.07\end{array}$ & $\begin{array}{l}-3.93 \\
-2.63 \\
-1.52 \\
-0.85 \\
-0.41\end{array}$ \\
\hline Most overpriced - most underpriced & -0.84 & -3.37 & 0.00 & 0.01 & -0.84 & -3.28 \\
\hline All stocks & -0.31 & -2.62 & 0.16 & 2.97 & -0.47 & -2.99 \\
\hline
\end{tabular}




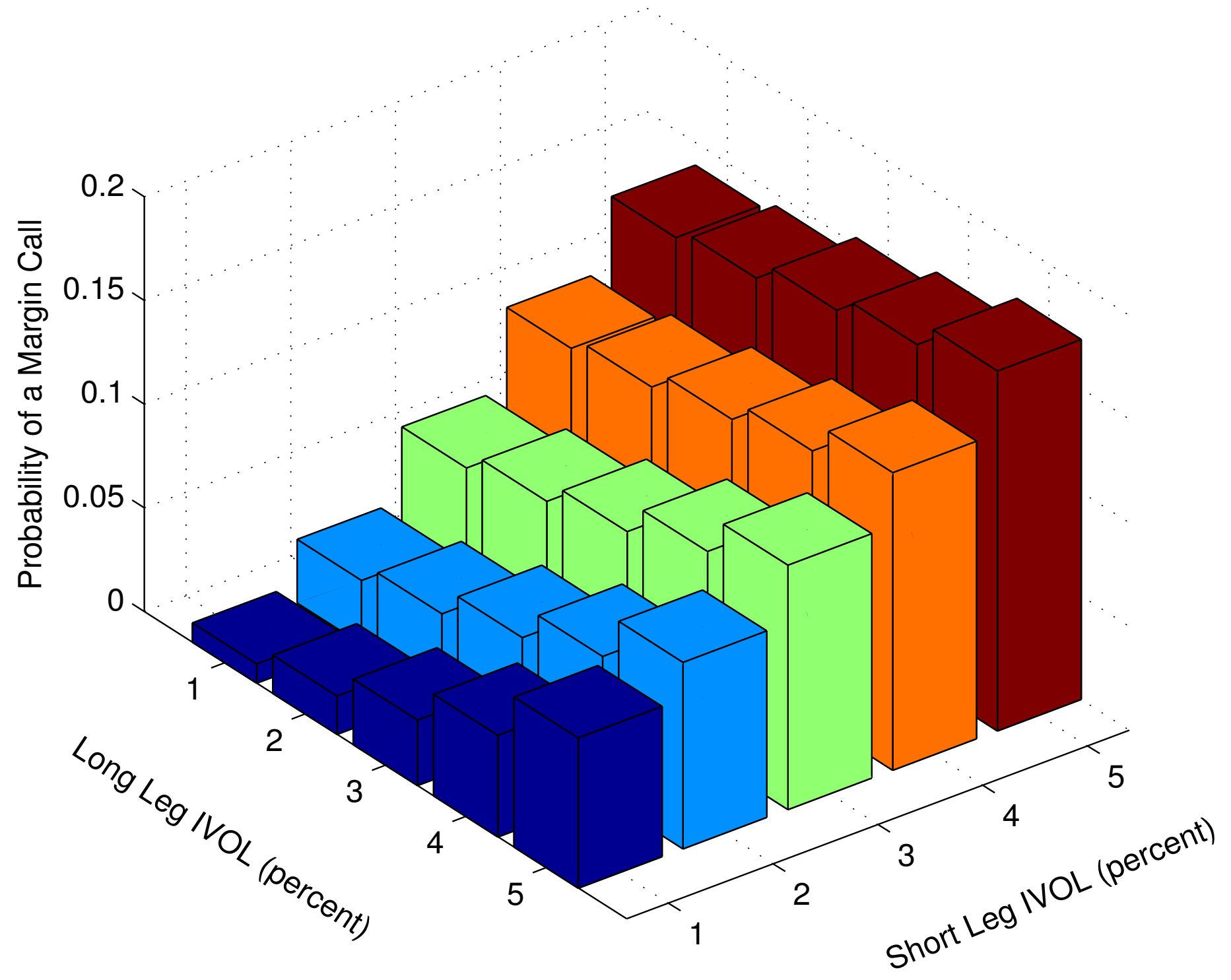

Figure 1. IVOL and the Probability of a Margin Call. The figure plots the probability of a long-short strategy hitting a $25 \%$ maintenance margin level within the next 12 months when the current margin level is $35 \%$. The current long and short positions are of equal size and have monthly IVOL values between $1 \%$ and $5 \%$. The long (short) leg has a monthly alpha of $0.5 \%$ $(-0.5 \%)$, and both legs have betas equal to 1 . The market portfolio's monthly return has a mean of $0.8 \%$ and a volatility of $5 \%$, and the monthly riskless rate is $0.3 \%$. 


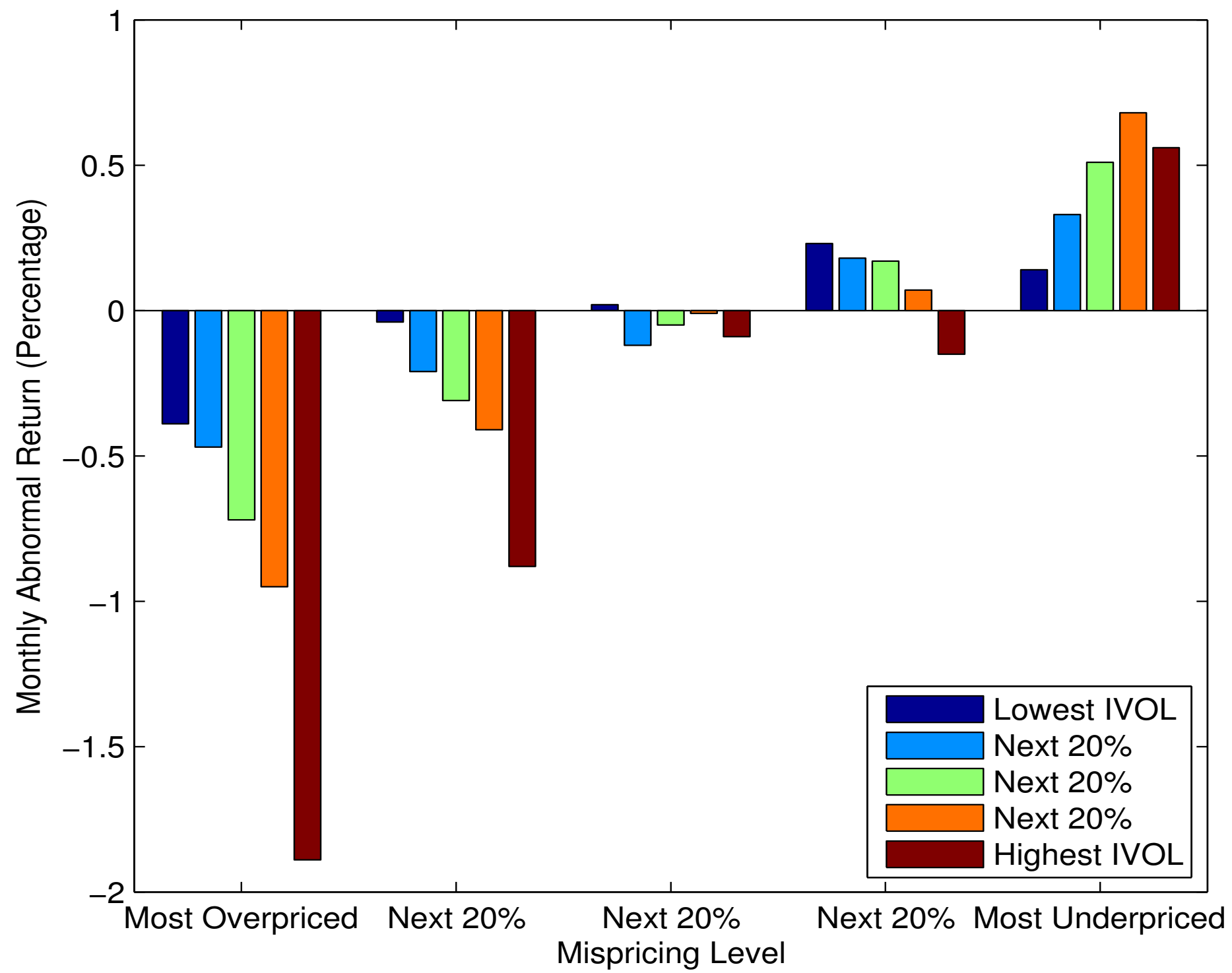

Figure 2. Monthly Abnormal Returns of Portfolios Ranked by Mispricing Level and IVOL. The figure plots the average monthly abnormal return on portfolios formed in a $5 \times 5$ sort that ranks independently by mispricing level and IVOL. Abnormal returns are calculated by adjusting for exposures to the three Fama-French factors. The average ranking percentile of 11 anomalies is used to measure the relative level of mispricing. The sample period covers 8/1965$1 / 2011$. 


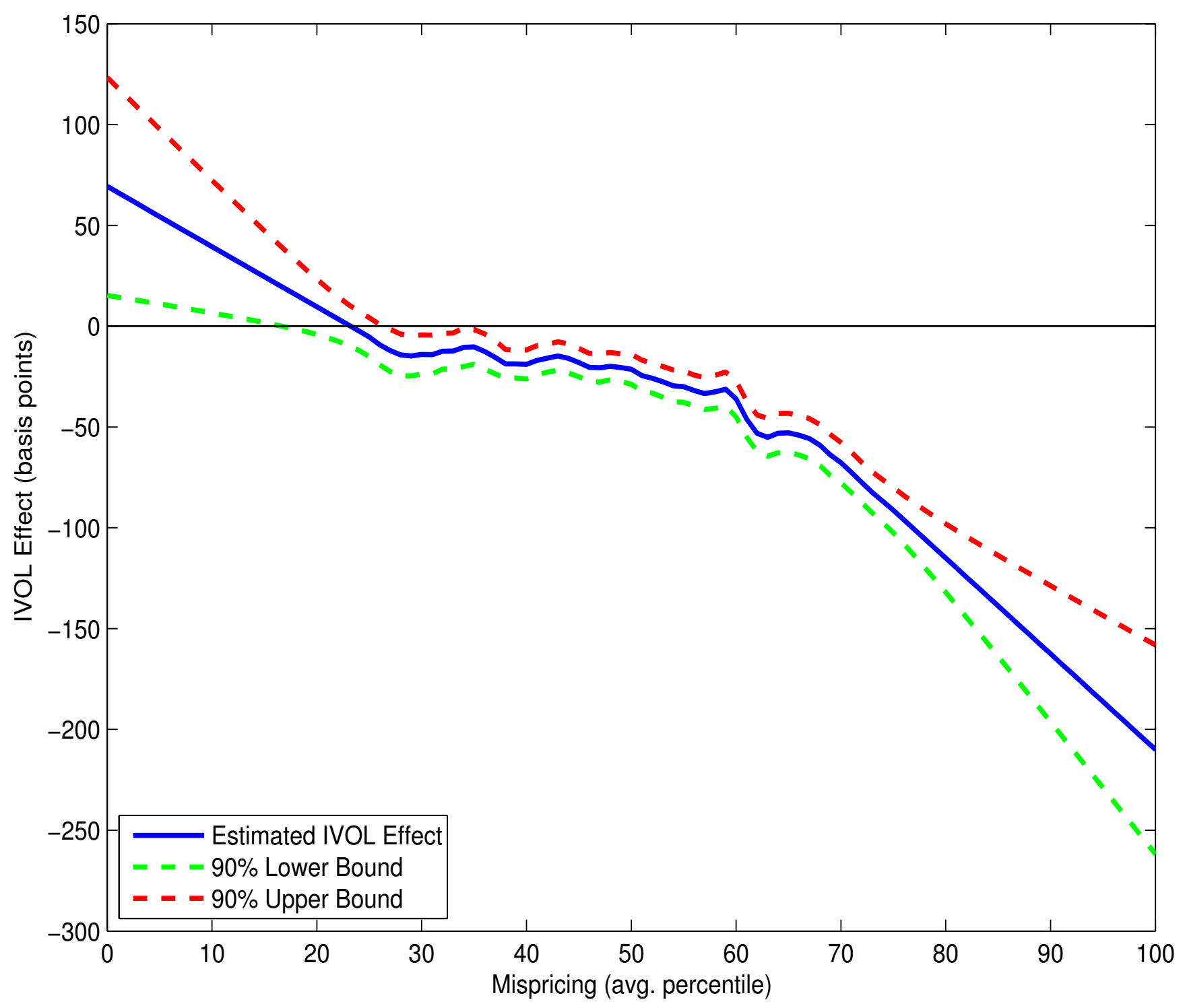

Figure 3. Estimated IVOL Effects. The figure plots estimates of $f(M)$, which is the effect of standardized IVOL on abnormal monthly return for a stock whose mispricing ranking percentile (averaged over 11 anomalies) is equal to $M$. Estimates are computed using the 8/1965-1/2011 sample period. 


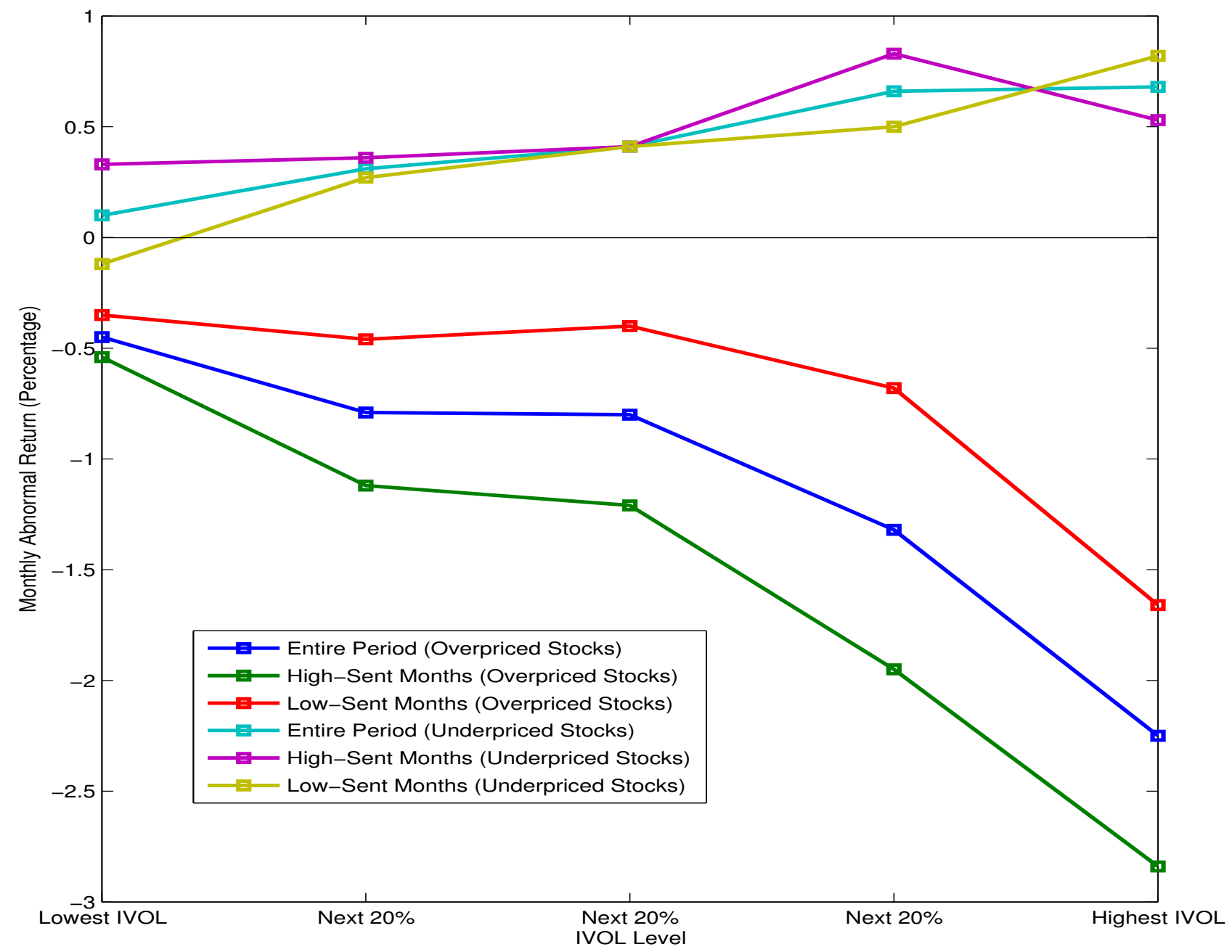

Figure 4. IVOL Effects and Investor Sentiment. The figure plots the average monthly abnormal return on portfolios formed in a $5 \times 5$ sort that ranks first by mispricing level and then by IVOL. Results are displayed for the five portfolios in the most underpriced quintile and the five portfolios in the most overpriced quintile. Abnormal returns are calculated by adjusting for exposures to the three Fama-French factors. The average ranking percentile of 11 anomalies is used to measure the relative level of mispricing. Averages are reported for the overall 8/1965$1 / 2011$ sample period as well as for high-sentiment and low-sentiment months classified using the Baker-Wurgler index. 


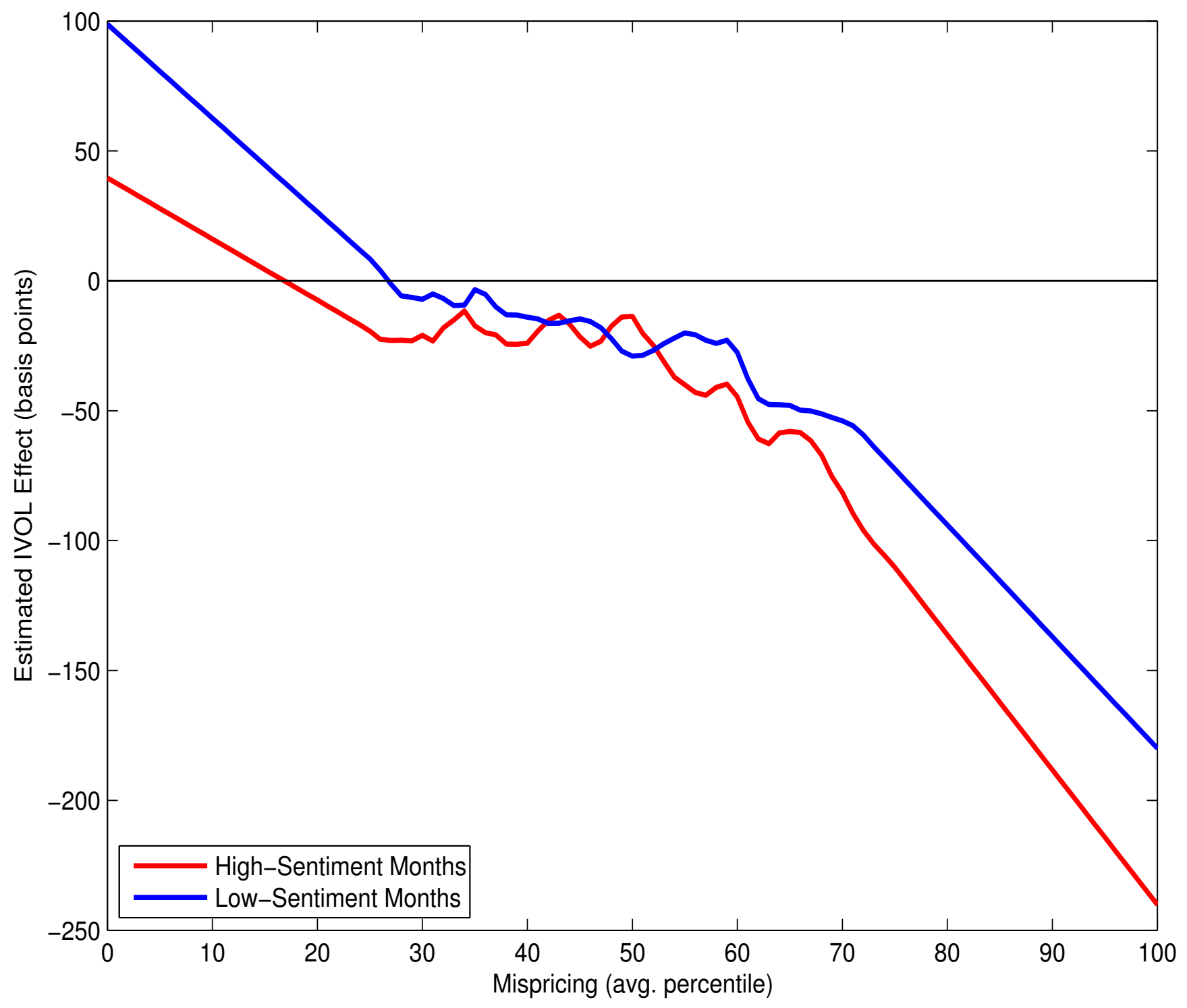

Figure 5. Estimated IVOL Effects Following High and Low Sentiment. The figure plots estimates of $f(M)$, which is the effect of standardized IVOL on abnormal monthly return for a stock whose mispricing ranking percentile (averaged over 11 anomalies) is equal to $M$. The estimates are computed separately in high-sentiment and low-sentiment months classified using the Baker-Wurgler index for the 8/1965-1/2011 sample period. 


\section{References}

Ahn, Dong-Hyun, Jennifer Conrad, and Robert F. Dittmar, 2009, Basis assets, Review of Financial Studies 22, 5133-5174.

Ali, Ashiq, Lee-Seok Hwang, and Mark A. Trombley, 2003, Arbitrage risk and the book-tomarket anomaly, Journal of Financial Economics 69, 355-373.

Almazan, Andres, Keith C. Brown, Murray Carlson, and David A. Chapman, 2004, Why constrain your mutual fund manager?, Journal of Financial Economics 73, 289-321.

Ang, Andrew, Robert J. Hodrick, Yuhang Xing, and Xiaoyan Zhang, 2006, The cross-section of volatility and expected returns, Journal of Finance 51, 259-299.

Antoniou, Constantinos, John A. Doukas, and Avanidhar Subrahmanyam, 2013, Cognitive dissonance, sentiment, and momentum, Journal of Financial and Quantitative Analysis $48,245-275$.

Antoniou, Constantinos, John A. Doukas, and Avanidhar Subrahmanyam, 2014, Investor sentiment, beta, and the cost of equity capital, Management Science, forthcoming.

Avramov, Doron, Tarun Chordia, Gergana Jostova, and Alexander Philipov, 2013, Anomalies and financial distress, Journal of Financial Economics 108, 139-159.

Baker, Malcolm, and Jeffrey Wurgler, 2006, Investor sentiment and the cross-section of stock returns, Journal of Finance 61, 1645-1680.

Baker, Malcolm, and Jeffrey Wurgler, 2007, Investor sentiment in the stock market, Journal of Economic Perspectives 21, 129-152.

Baker, Malcolm, Jeffrey Wurgler, and Yu Yuan, 2012, Global, local, and contagious investor sentiment, Journal of Financial Economics 104, 272-287.

Bali, Turan G., and Nusret Cakici, 2008, Idiosyncratic volatility and the cross-section of expected returns, Journal of Financial and Quantitative Analysis 43, 29-58.

Bali, Turan G., Nusret Cakici, and Robert F. Whitelaw, 2011, Maxing out: Stocks as lotteries and the cross-section of expected returns, Journal of Financial Economics 99, 427-446.

Bali, Turan G., Anna Scherbina, and Yi Tang, 2011, Unusual news events and the crosssection of stock returns, Working paper, Georgetown University, University of California, and Fordham University.

Barberis, Nicholas, and Ming Huang, 2001, Mental accounting, loss aversion, and individual stock returns, Journal of Finance 56, 1247-1292.

Barberis, Nicholas, and Ming Huang, 2008, Stocks as lotteries: The implications of probability weighting for security prices, American Economic Review 98, 2066-2100.

Barinov, Alexander, 2013, Idiosyncratic volatility, growth options, and the cross-section of returns, Working paper, University of Georgia.

Ben-David, Itzhak, and Darren Roulstone, 2010, Idiosyncratic risk and corporate transactions, Working Paper, Ohio State University.

Beneish, Messod Daniel, Charles M.C. Lee, and Craig Nichols, 2013, In short supply: Equity overvaluation and short selling, Working paper, Indiana University, Stanford University, and Syracuse University. 
Bergman, Nittai K., and Sugata Roychowdhury, 2008, Investor sentiment and corporate disclosure, Journal of Accounting Research 46, 1057-1083.

Boehme, Rodney, Bartley Danielsen, Praveen Kumar, and Sorin Sorescu, 2009, Idiosyncratic risk and the cross-section of stock returns: Merton (1987) meets Miller (1977), Journal of Financial Markets 12, 438-468.

Boyer, Brian, Todd Mitton, and Keith Vorkink, 2010, Expected idiosyncratic skewness, Review of Financial Studies 23, 169-202.

Brandt, Michael W., Alon Brav, John R. Graham, and Alok Kumar, 2010, The idiosyncratic volatility puzzle: Time trend or speculative episodes?, Review of Financial Studies 23, 863-899.

Campbell, John Y. and John Cochrane, 1999, By force of habit: A consumption-based explanation of aggregate stock market behavior, Journal of Political Economy 107, 205251.

Campbell, John Y., Jens Hilscher, and Jan Szilagyi, 2008, In search of distress risk, Journal of Finance 63, 2899-2939.

Cao, Xuying, and Yexiao Xu, 2010, Long-run idiosyncratic volatilities and cross-sectional stock returns, Working paper, University of Texas at Dallas.

Cao, Jie, and Bing Han, 2014, Expected idiosyncratic risk, costly arbitrage, and the crosssection of stock returns, Working paper, Chinese University of Hong Kong and University of Toronto.

Chen, Long, Robert Novy-Marx, and Lu Zhang, 2010, An alternative three-factor model, Working paper, CKGSB, University of Rochester, and Ohio State University.

Chen, Joseph, Harrison Hong, and Jeremy C. Stein, 2002, Breadth of ownership and stock returns, Journal of Financial Economics 66, 171-205.

Chen, Linda, George J. Jiang, Danielle Xu, and Tong Yao, 2012, Dissecting the idiosyncratic volatility anomaly, Working paper, Washington State University, Gonzaga University, and University of Iowa.

Chen, Zhanhui, and Ralitsa Petkova, 2012, Does idiosyncratic volatility proxy for risk exposure?, Review of Financial Studies 25, 2745-2787.

Chung, San-Lin, Chi-Hsiou Hung, and Chung-Ying Yeh, 2012, When does investor sentiment predict stock returns?, Journal of Empirical Finance 19, 217-240.

Cooper, Michael J., Huseyin Gulen, and Michael J. Schill, 2008, Asset growth and the crosssection of stock returns, Journal of Finance 63, 1609-1652.

Daniel, Kent D., and Sheridan Titman, 2006, Market reactions to tangible and intangible information, Journal of Finance 61, 1605-1643.

Dechow, Patricia M., Amy P. Hutton, Lisa Meulbroek, and Richard G. Sloan, 2001, Shortsellers, fundamental analysis, and stock returns, Journal of Financial Economics 61, $77-106$.

DeLong, Bradford, Andrei Shleifer, Lawrence H. Summers, and Robert Waldmann, 1990, Noise trader risk in financial market, Journal of Political Economy 90, 703-738. 
Diether, Karl B., Christopher J. Malloy, and Anna Scherbina, 2002, Differences of opinion and the cross-section of stock returns, Journal of Finance 57, 2113-2141.

Douglas, George W., 1968, Risk in the Equity Markets: An Empirical Appraisal of Market Efficiency, (University Microfilms Inc., Ann Arbor).

Drechsler, Itamar, and Qingyi Freda Drechsler, 2014, The shorting premium and asset pricing anomalies, Working paper, New York University and Wharton Research Data Services.

Duan, Ying, Gang Hu, and R. David McLean, 2010, Costly arbitrage and idiosyncratic risk: evidence from short sellers, Journal of Financial Intermediation 19, 564-579.

Duffie, Darrell, Nicolae Garleanu, and Lasse Heje Pedersen, 2002, Securities lending shorting and pricing, Journal of Financial Economics 66, 307-339.

D'Avolio, Gene, 2002, The market for borrowing stock, Journal of Financial Economics 66, $271-306$.

Engleberg, Joseph E., Adam V. Reed, and Matthew C. Ringgenberg, 2013, Short selling risk, Working paper, University of California, San Diego, University of North Carolina, and Washington University in St. Louis.

Ewens, Michael, Jones, Charles M., and Matthew Rhodes-Kropf, 2013, The price of diversifiable risk in venture capital and private equity, Review of Financial Studies 26, $1854-1889$.

Fama, Eugene F., and Kenneth French, 1993, Common risk factors in the returns on stocks and bonds, Journal of Financial Economics 33, 3-56.

Fama, Eugene F., and Kenneth French, 2006, Profitability, investment, and average returns, Journal of Financial Economics 82, 491-518.

Fama, Eugene F., and Kenneth French, 2008, Dissecting anomalies, Journal of Finance 63, $1653-1678$.

Fama, Eugene F., and James D. MacBeth, 1973, Risk, return, and equilibrium: Empirical tests, The Journal of Political Economy 81, 607-636.

Figlewski, Stephen, 1981, The informational effects of restrictions on short sales: Some empirical evidence, Journal of Financial and Quantitative Analysis 16, 463-476.

Fink, Jason D., Kristin E. Fink, and Hui He, 2012, Expected idiosyncratic volatility measures and expected returns, Financial Management 41, 519-553.

Frazzini, Andrea, and Owen Lamont, 2008, Dumb money: Mutual fund flows and the cross section of stock returns, Journal of Financial Economics 88, 299-322.

Fu, Fangjian, 2009, Idiosyncratic risk and the cross-section of expected stock returns, Journal of Financial Economics 91, 24-37.

Han, Yufeng, and David Lesmond, 2011, Liquidity biases and the pricing of cross-sectional idiosyncratic volatility, Review of Financial Studies 24, 1590-1629.

Hanna, J. Douglas, and Mark J. Ready, 2005, Profitable predictability in the cross section of stock returns, Journal of Financial Economics 78, 463-505.

Haugen, Robert A., and Nardin L. Baker, 1996, Commonality in the determinants of expected stock returns, Journal of Financial Economics 41, 401-439. 
Hirshleifer, David, Kewei Hou, Siew Hong Teoh, and Yinglei Zhang, 2004, Do investors overvalue firms with bloated balance sheets, Journal of Accounting and Economics 38, 297-331.

Hong, Harrison, and David Sraer, 2014, Speculative betas, Working paper, Princeton University and University of California, Berkeley.

Huang, Wei, Qianqiu Liu, S. Ghon Rhee, and Liang Zhang, 2010, Return reversals, idiosyncratic risk, and expected returns, Review of Financial Studies 23, 147-168.

Guo, Hui, and Robert Savickas, 2010, Relation between time-series and cross-sectional effects of idiosyncratic variance on stock returns, Journal of Banking and Finance 34, 1637-1649.

Guo, Hui, Haimanot Kassa, and Michael Ferguson, 2014, On the relation between EGARCH idiosyncratic volatility and expected stock returns, Journal of Financial and Quantitative Analysis 49, 271-296.

Hirsheifer, David, Siew Hong Toeh, and Jeff Jiewei Yu, 2011, Short arbitrage, return asymmetry, and the accrual anomaly, Review of Financial Studies 24, 2429-2461.

Jegadeesh, Narasimhan, and Sheridan Titman, 1993, Returns to buying winners and selling losers: Implications for market efficiency, Journal of Finance 48, 65-91.

Jiang, George J., Danielle Xu, and Tong Yao, 2009, The information content of idiosyncratic volatility, Journal of Financial and Quantitative Analysis 44, 1-28.

Jin, Lucy, 2013, Idiosyncratic volatility, arbitrage risk, and anomaly returns, unpublished doctoral thesis, University of Pennsylvania.

Jones, Charles M., and Owen A. Lamont, 2002, Short-sale constraints and stock returns, Journal of Financial Economics 66, 207-239.

Kaniel, Ron, Gideon Saar, and Sheridan Titman, 2008, Individual investor trading and stock returns, Journal of Finance 63, 273-310.

Keynes, John M., 1936, The General Theory of Employment, Interest and Money, (Macmillan, London).

Koski, Jennifer Lynch, and Jeffrey Pontiff, 1999, How are derivatives used? Evidence from the mutual fund industry, Journal of Finance 54, 791-816.

Lam, Eric, and John Wei, 2011, Limits-to-arbitrage, investment frictions, and the asset growth anomaly, Journal of Financial Economics 102, 127-149.

Lamont, Owen, 2012, Going down fighting: short sellers vs. firms, Review of Asset Pricing Studies 2, 1-30.

Lamont, Owen, and Jeremy C. Stein, 2004, Aggregate short interest and market valuation, American Economic Review Papers and Proceedings 94, 29-32.

Larrain, Borja, and Felipe Varas, 2013, Equity issues and return volatility, Review of Finance $17,767-808$.

Lehmann, Bruce N., 1990, Residual risk revisited, Journal of Econometrics 45, 71-97.

Lemmon, Michael L., and Evgenia Portniaguina, 2006, Consumer confidence and asset prices: Some empirical evidence, Review of Financial Studies 19(4), 1499-1529. 
Lettau, Martin, and Sydney Ludvigson, 2001, Consumption, aggregate wealth, and expected stock returns, Journal of Finance 56(3), 815-849.

Lewellen, Jonathan, 2014, The cross section of expected stock returns, Critical Finance Review, forthcoming.

Li, Dongmei, and Lu Zhang, 2010, Does Q-theory with investment frictions explain anomalies in the cross-section of returns?, Journal of Financial Economics 98, 297-314.

Li, Xi, and Rodney N. Sullivan, 2011, The limits to arbitrage revisited: The accrual and asset growth anomalies, Financial Analysts Journal 67(4), 50-66.

Lintner, John, 1965, The valuation of risk assets and the selection of risky investments in stock portfolios and capital budgets, Review of Economics and Statistics 47, 13-37.

Lipson, Marc, Sandra Mortal, and Michael Schill, 2011, On the scope and drivers of the asset growth effect, Journal of Financial and Quantitative Analysis, 1651-1682.

Livnat, Joshua, and Christine Petrovits, 2008, Investor sentiment, post-earnings announcement drift, and accruals, Working paper, New York University and College of William and Mary

Loughran, Tim, and Jay R. Ritter, 1995, The new issues puzzle, Journal of Finance 50, $23-51$.

Mashruwala, Christina, Shivaram Rajgopal, and Terry Shevlin, 2006, Why is the accrual anomaly not arbitraged away? The role of idiosyncratic risk and transaction costs, Journal of Accounting and Economics 42, 3-33.

Malkiel, Burton G., and Yexiao Xu, 2002, Idiosyncratic risk and security returns, Working paper, University of Texas at Dallas.

McLean, R. David, 2010, Idiosyncratic risk, long-term reversal, and momentum, Journal of Financial and Quantitative Analysis 45, 883-906.

Mendenhall, Richard R., 2004, Arbitrage risk and post-earnings-announcement drift, Journal of Business 77, 875-894.

Merton, Robert C., 1987, A simple model of capital market equilibrium with incomplete information, Journal of Finance 42, 483-510.

Miller, Edward M., 1977, Risk, uncertainty and divergence of opinion, Journal of Finance $32,1151-1168$.

Miller, Merton H. and Myron Scholes, 1972, Rates of return in relation to risk: A Reexamination of some recent findings, in Michael C. Jenson, eds.: Studies in the Theory of Capital Markets, (Praeger, New York).

Mitchell, Mark, Todd Pulvino, and Erik Stafford, 2002, Limited arbitrage in equity markets, Journal of Finance 57, 551-584.

Nagel, Stefan, 2005, Short sales, institutional investors and the cross-section of stock returns, Journal of Financial Economics 78, 277-309.

Newey, Whitney K., and Kenneth D. West, 1987, A simple positive semi-definite, heteroskedasticity and autocorrelation consistent covariance matrix, Econometrica 55, 703708. 
Novy-Marx, Robert, 2013, The other side of value: The gross profitability premium, Journal of Financial Economics 108, 1-28.

Novy-Marx, Robert, 2014, Predicting anomaly performance with politics, the weather, global warming, sunspots, and the stars, Journal of Financial Economics 112, 137-146.

Ofek, Eli, Matthew Richardson, and Robert F. Whitelaw, 2004, Limited arbitrage and short sales restrictions: Evidence from the options markets, Journal of Financial Economics $74,305-342$.

Ohlson, James A., 1980, Financial ratios and the probabilistic prediction of bankruptcy, Journal of Accounting Research 18, 109-131.

Pincus, Morton, Shivaram Rajgopal, and Mohan Venkatachalam, 2007, The accrual anomaly: International evidence, The Accounting Review 82, 169-203.

Pontiff, Jeffrey, 1996, Costly arbitrage: Evidence from closed-end funds, Quarterly Journal of Economics 111, 1135-1152.

Pontiff, Jeffrey, 2006, Costly arbitrage and the myth of idiosyncratic risk, Journal of Accounting and Economics 42, 35-52.

Rachwalski, Mark, and Quan Wen, 2013, Idiosyncratic risk innovations and the idiosyncratic risk-return relation, Working paper, Emory University and Georgetown University.

Ritter, Jay R., 1991, The long-run performance of initial public offerings, Journal of Finance $46,3-27$.

Savor, Pavel, and Mario Gamboa-Cavazos, 2014, Holding on to your shorts: When do short sellers retreat?, Working paper, Temple University and AQR Capital Management, LLC.

Scheinkman, Jose, and Wei Xiong, 2003, Overconfidence and speculative bubbles, Journal of Political Economy 111, 1183-1219.

Scruggs, John T., 2007, Noise trader risk: Evidence from the Siamese twins, Journal of Financial Markets 10, 76-105.

Shen, Junyan, and Jianfeng Yu, 2012, Investor sentiment and economic forces, Working paper, University of Minnesota.

Shleifer, Andrei, and Robert Vishny, 1997, The limits of arbitrage, Journal of Finance, 52, $35-55$.

Sibley, Steve E., Yuhang Xing, and Xiaoyan Zhang, 2012, Is "sentiment" sentimental?, Working paper, Purdue University and Rice University.

Sloan, Richard G., 1996, Do stock prices fully reflect information in accruals and cash flows about future earnings?, Accounting Review 71, 289-315.

Stambaugh, Robert F., Jianfeng Yu, and Yu Yuan, 2012, The short of it: Investor sentiment and anomalies, Journal of Financial Economics 104, 288-302.

Stambaugh, Robert F., Jianfeng Yu, and Yu Yuan, 2014, The long of it: Odds that investor sentiment spuriously predicts anomaly returns, Journal of Financial Economics 114, 613-619.

Tinic, Seha M., and Richard R. West, 1986, Risk, return, and equilibrium: A revisit, Journal of Political Economy 94, 126-147. 
Titman, Sheridan, K. C. John Wei, and Feixue Xie, 2004, Capital investments and stock returns, Journal of Financial and Quantitative Analysis 39, 677-700.

Wachter, Jessica, 2006, A consumption-based model of the term structure of interest rates, Journal of Financial Economics 79, 365-399.

Wang, Huijun, and Jianfeng Yu, 2010, Dissecting the profitability premium, Working paper, University of Minnesota.

Ward, Joe H., 1963, Hierarchical grouping to optimize and objective function, Journal of the American Statistical Association 58, 236-244.

White, Halbert, 1980, A heteroskedasticity-consistent covariance matrix estimator and a direct test for heteroskedasticity, Econometrica 48, 817-838.

Wurgler, Jeffrey, and Ekaterina Zhuravskaya, 2002, Does arbitrage flatten demand curves for stocks?, Journal of Business 75, 583-608.

Xing, Yuhang, 2008, Interpreting the value effect through the Q-theory: An empirical investigation, Review of Financial Studies 21, 1767-1795.

Zhang, Frank, 2006, Information uncertainty and stock returns, Journal of Finance 61, 105-136. 


\section{Footnotes}

1 The classic study finding no relation between expected return and IVOL is Fama and MacBeth (1973), who acknowledge the methodological issues raised by Miller and Scholes (1972) in their reexamination of Douglas (1968). A more recent study finding no relation is Bali and Cakici (2008). Studies finding a positive relation include Lintner (1965), Tinic and West (1986), Lehmann (1990), Malkiel and Xu (2002), and Fu (2009).

2 Explanations for a positive relation include Merton (1987), Barberis and Huang (2001), Malkiel and Xu (2002), and Ewens, Jones, and Rhodes-Kropf (2013).

${ }^{3}$ Studies addressing the role of arbitrage risk in mispricing include DeLong, Shleifer, Summers, and Waldmann (1990), Pontiff (1996), Shleifer and Vishny (1997), Mitchell, Pulvino, and Stafford (2002), and Wurgler and Zhuravskaya (2002).

${ }^{4}$ Studies addressing the role of such asymmetry in the equity market include Miller (1977), Figlewski (1981), Chen, Hong, and Stein (2002), D'Avolio (2002), Diether, Malloy, and Scherbina (2002), Duffie, Garleanu, and Pedersen (2002), Jones and Lamont (2002), Scheinkman and Xiong (2003), Lamont and Stein (2004), Ofek, Richardson, and Whitelaw (2004), Nagel (2005), Lamont (2012), Stambaugh, Yu, and Yuan (2012), and Avramov, Chordia, Jostova, and Philipov (2013).

${ }^{5}$ Related studies that investigate the role of investor sentiment in cross-sectional returns include Baker and Wurgler (2006, 2007), Lemmon and Portniaguina (2006), Bergman and Roychowdhury (2008), Kaniel, Saar, and Titman (2008), Frazzini and Lamont (2008), Livnat and Petrovic (2008), Baker, Wurgler, and Yuan (2012), Chung, Hung, and Yeh (2012), Shen and Yu (2012), Stambaugh, Yu, and Yuan (2012, 2014), and Antoniou, Doukas, and Subrahmanyam $(2013,2014)$.

${ }^{6}$ Specifying $\Sigma$ as literally diagonal (and thus nonsingular) must be an approximation, given that the capitalization-weighted average of market-adjusted returns must be zero, so we are assuming the approximation error is negligible.

${ }^{7}$ Engleberg, Reed, and Ringgenberg (2013) discuss additional risks of short positions, including fee increases and recalls of stock loans. Recall risk includes the possibility of occasional squeezes, as discussed for example by Dechow, Hutton, Meulbroek, and Sloan (2001), who cite circumstances surrounding the stock of Amazon.com in June 1998 as a notable instance .

${ }^{8}$ In analyzing the effect of shocks to IVOL on stock returns, Bali, Scherbina, and Tang (2011) also argue that stocks with high IVOL have a higher probability of margin calls on 
short positions.

9 The asymmetry increases if the example also incorporates the fact that the Financial Industry Regulatory Authority (FINRA), which regulates U.S. brokerage firms, specifies a maintenance requirement of $25 \%$ for long positions but $30 \%$ for short positions. (See FINRA Rule 4210.)

${ }^{10}$ The t-statistics are based on White (1980) standard errors, but the results are very similar if we use Newey-West (1987) standard errors with either 3 or 6 lags. The results are shown in the on-line appendix. This insensitivity is consistent with the low serial correlations of the returns on the 25 portfolios. The first-order autocorrelation for these portfolios has an average of $2.3 \%$ and ranges from $-9.1 \%$ to $12.5 \%$.

${ }^{11}$ Equally weighted portfolios yield similar results to the value-weighted results in Table II: a significantly positive IVOL effect among the most underpriced stocks, a stronger negative IVOL effect among the most overpriced, and significantly negative overall IVOL effect. Details are provided in the online appendix.

${ }^{12}$ Such an approach is similar to that in Haugen and Baker (1996), Hanna and Ready (2005), and Lewellen (2014).

${ }^{13}$ Related results linking shorting impediments to anomaly profits are reported by Beneish, Lee, and Nichols (2013), who find stronger short-leg anomaly profits among hard-to-borrow ("special") stocks, and by Drechsler and Drechsler (2014), who also find that anomaly profits are significantly increasing in stock-lending fees. The relatively short sample periods in both studies begin in 2004, due to the availability of equity-lending data, whereas the IO data used here begin in 1980 .

${ }^{14}$ The bond yields are obtained from the St. Louis Federal Reserve, the T-bill return and inflation are obtained from CRSP, and Cay is obtained from Sydney Ludvigson's website. Following Wachter (2006), the surplus ratio is calculated as a smoothed average of past consumption growth.

${ }^{15}$ Additional stock-market variables included by Sibley, Xing, and Zhang (2012) are volatility and a liquidity measure. Liquidity in particular could contain sentiment effects. In fact, Baker and Wurgler (2006) include turnover as one of the variables constituting their sentiment index. 